Genetic Analysis of Sucrose Concentration in Soybean Seeds Using a Historical Soybean Genomic Panel

$$
\text { by }
$$

Alexandra Michelle Ficht

\author{
A Thesis \\ presented to \\ The University of Guelph \\ In partial fulfilment of requirements \\ for the degree of \\ Master of Science \\ in \\ Plant Agriculture
}

Guelph, Ontario, Canada

(C) Alexandra Michelle Ficht, May, 2018 


\section{ABSTRACT \\ GENETIC ANALYSIS OF SUCROSE CONCENTRATION IN SOYBEAN SEEDS USING A HISTORICAL SOYBEAN GENOMIC PANEL}

\section{Alexandra Michelle Ficht \\ University of Guelph, 2018}

Advisor:

Professor I. Rajcan

Sucrose concentration in soybean (Glycine max L. Merr) seed is becoming an increasingly important trait for the soy food industry. The objectives of this thesis were to: 1) identify quantitative trait loci (QTL) for sucrose concentration, 2) explore the allelic variation present in a genomic panel for candidate genes related to sucrose synthesis in soybean, and 3) determine the effect of genotype (G), environment (E) and genotype-by-environment interaction (GE) on varying sucrose levels in the seed. A University of Guelph panel of 296 pedigree-related genotypes was used for this analysis. Significant G, E, and GE interaction effects were observed for sucrose over three years and four locations in Ontario, which allowed for determining the trait stability. QTL analysis was performed using single nucleotide polymorphisms (SNPs) detected using a genotyping-by-sequencing (GBS) approach. A putative QTL was identified in the genomic region harbouring a potential gene involved in sucrose metabolism. Improved understanding of the genetics of sucrose biosynthesis allows for the future development of high sucrose soybean cultivars. 


\section{Acknowledgements}

I would like to sincerely thank my advisor, Professor Istvan Rajcan, for his tremendous support and constant encouragement throughout my degree.

I would also like to express my sincerest thanks to Professors Alireza Navabi, and Lewis Lukens for serving on my MSc advisory committee and providing feedback and their expertise throughout the process.

During the past two years, I have been blessed to have help by many lab mates and field crew who contributed directly to my research, notably Chris Grainger, Robert Bruce, Davoud Torkamaneh, André Passianotto, Yesenia Salazar, Martha Jiminez, Mei Wang, Colbey Templeman Sebben, Cory Schilling, Lin Liao, Chanditha Priyanatha, and Alex Harris.

I would like to recognize our funding partners, without whom this project would not have been possible: SeCan, OMAFRA, NSERC, GFO and Huron Commodities Ltd.

And of course, thank you to all my family and friends for their continuous support, especially my parents Christine and Wes Gee and Kevin and Faye Ficht. Finally, Keifer Quick who has shared his love and patience with me through both good times and bad. 


\section{TABLE OF CONTENTS}

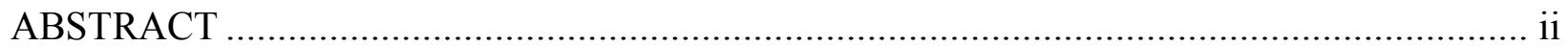

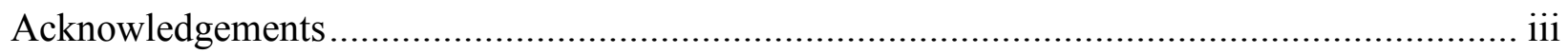

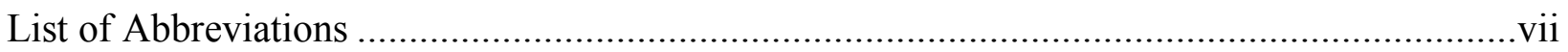

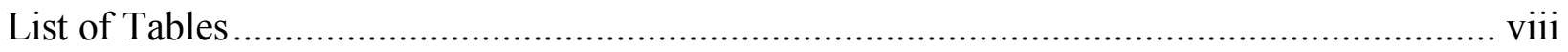

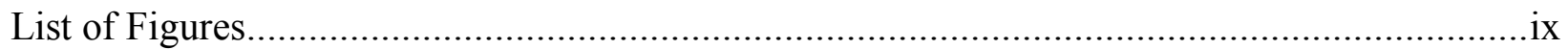

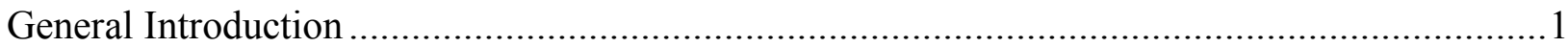

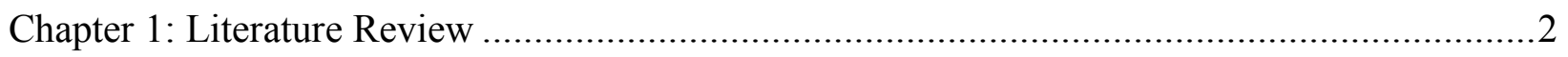

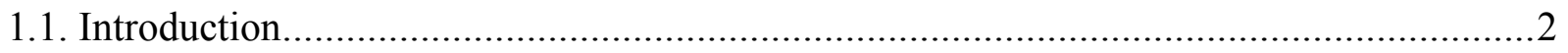

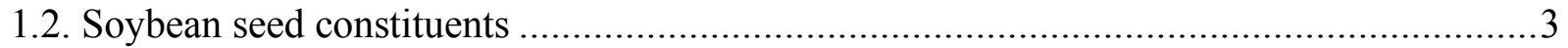

1.3. Sucrose concentration in food-grade cultivars............................................................

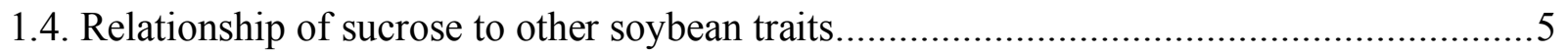

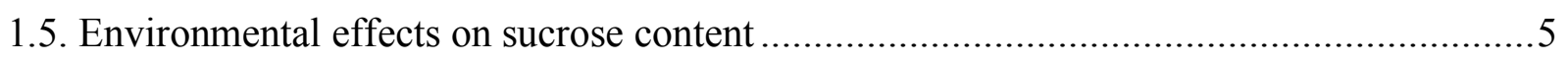

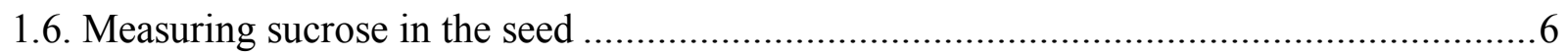

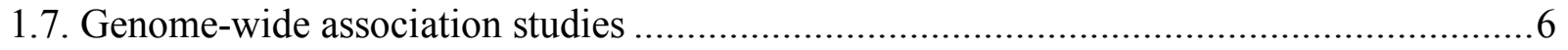

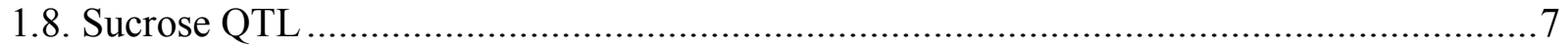

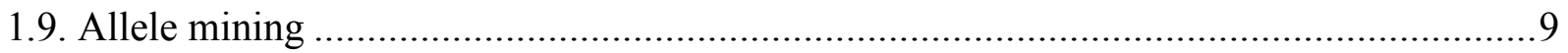

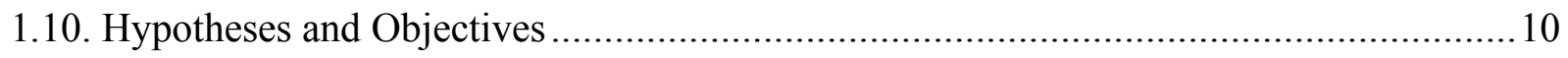

Chapter 2: Candidate QTL for Sucrose Concentration in Soybean Seed ....................................11

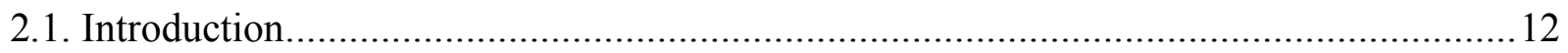

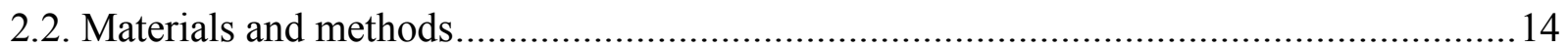

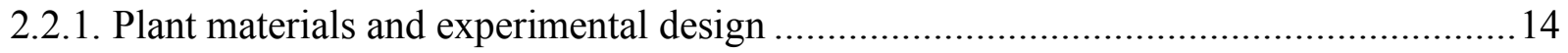

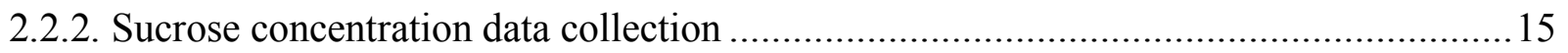

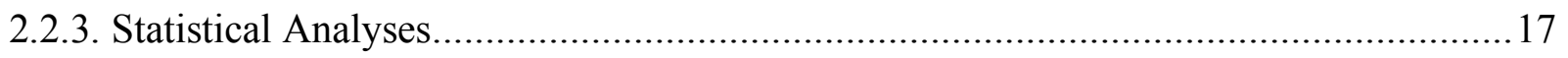

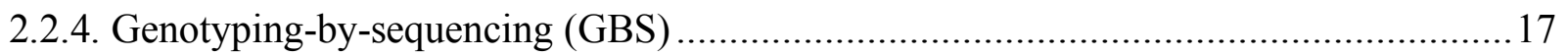

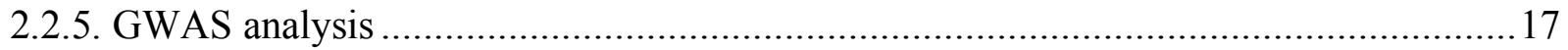

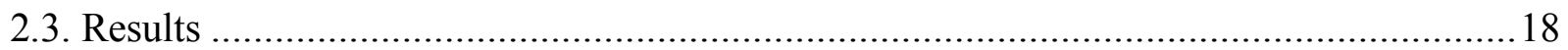

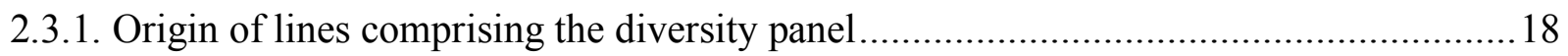

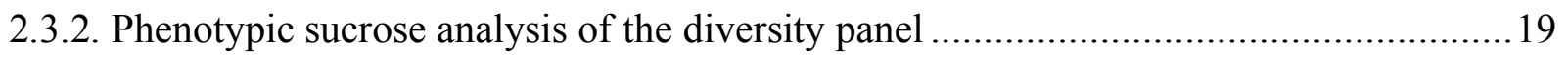

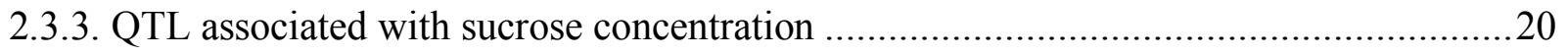


Chapter 3: Allelic Diversity for Sucrose Content in the Soybean Seed...................................30

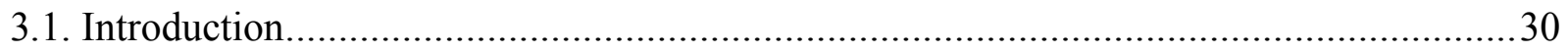

3.2. Materials and Methods ...................................................................................... 33

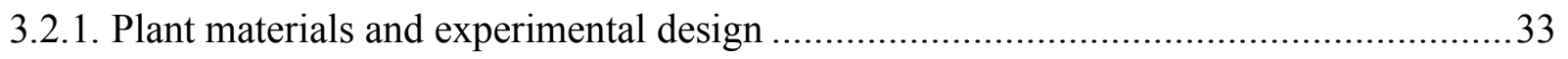

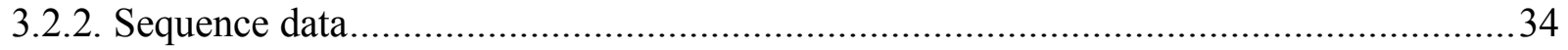

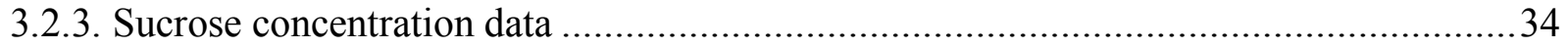

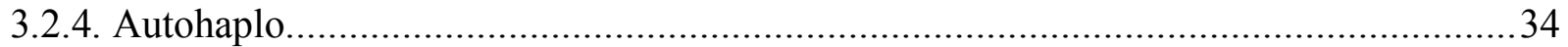

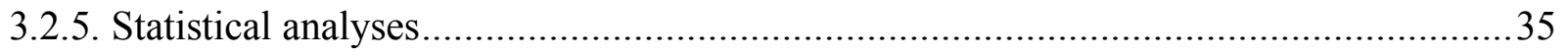

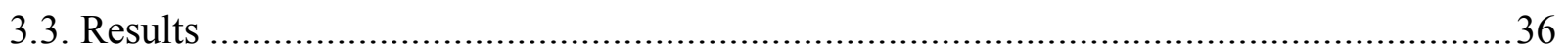

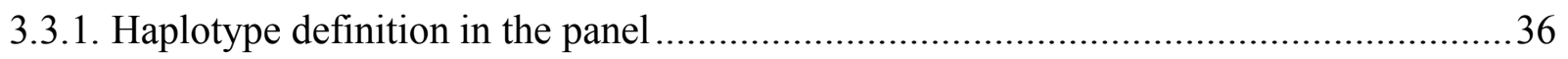

3.3.2. Phenotypic distribution based on haplotype group ............................................ 36

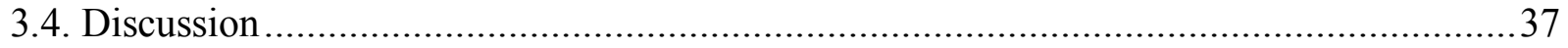

Chapter 4: Genotype-by-Environment Effect on Sucrose Concentration...............................43

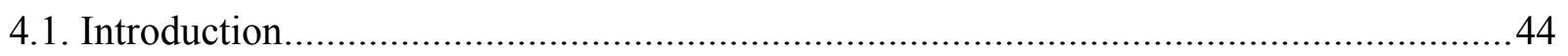

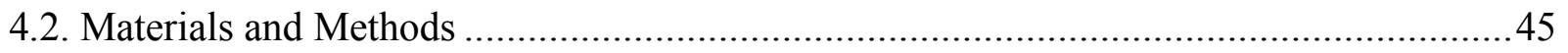

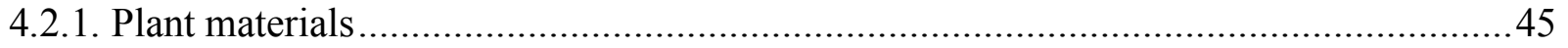

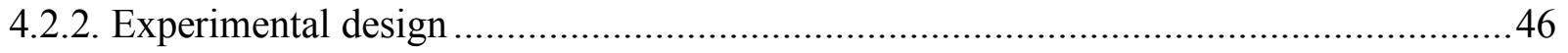

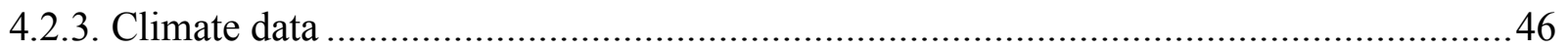

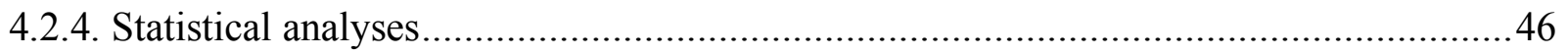

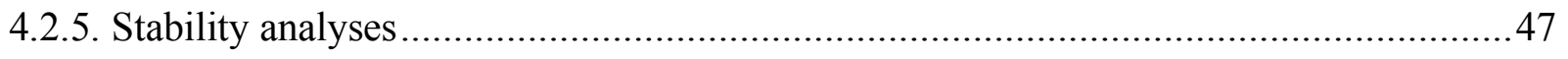

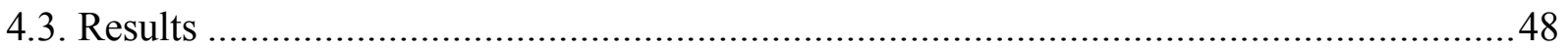

4.3.1. Environmental influence on sucrose concentration in the seed ..............................48

4.3.2. Genotype, environment, and genotype-by-environment interaction variance analysis

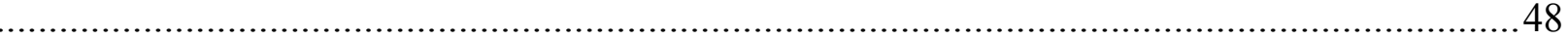

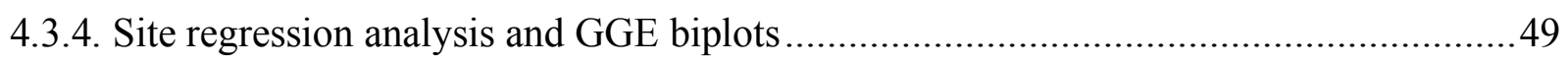

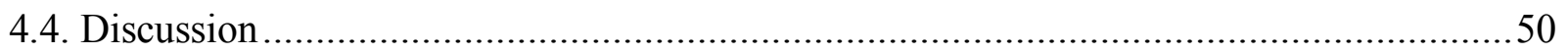

Chapter 5: General Discussion and Future Directions................................................61

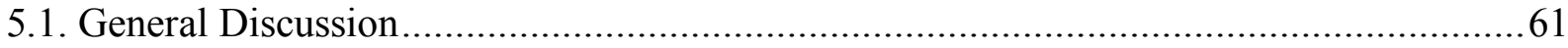

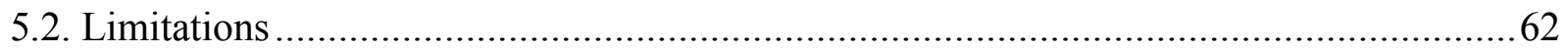




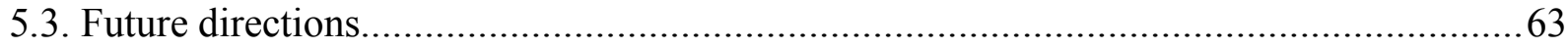

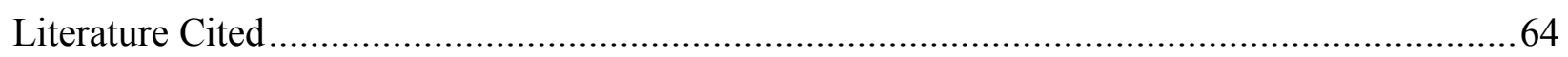

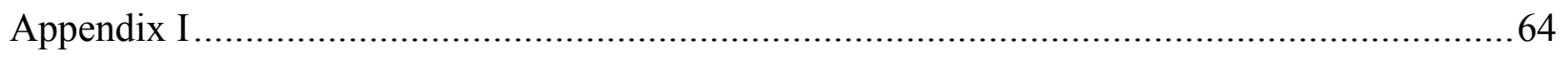




\section{List of Abbreviations}

AAFC, Agriculture and Agri-Food Canada

ANOVA, analysis of variance

E, environment

ECMLM, enriched compressed MLM

G, genotype

GAPDH, glyceraldehyde-3-phosphate dehydrogenase

GAPIT, genomic association and prediction integrated tool

GE, genotype-by-environment

GBS, genotyping-by-sequencing

GWAS, genome-wide association study

HPLC, high performance liquid chromatography

LD, linkage disequilibrium

LSMEAN, least significant mean

MAF, minor allele frequency

MAS, marker assisted selection

MLM, mixed linear model

MLMM, multi-locus mixed model

NIRS, near-infrared reflectance spectroscopy

PCA, principal component analysis

QTL, quantitative trait locus

RCBD, randomized complete block design

RFLP, restriction fragment length polymorphism

RIL, recombinant inbred line

SNP, single nucleotide polymorphism

SSR, simple sequence repeat

SUPER, settlement of MLM under progressively exclusive relationship 


\section{List of Tables}

Table 2.1. Lines that were removed from the University of Guelph panel analysis due to insufficient growth in the field, or inaccurate readings from the DA7250 Perten NIR analyzer.. 23

Table 2.2. Sucrose concentration for the University of Guelph panel in individual environments, combined years, combined locations and all environments. The lines were grown at Chatham and Ridgetown in 2015 and 2016 and St. Pauls and Woodstock from 2015 to 2017. Data represent the minimum, maximum, mean and standard errors $(\alpha=0.05)$

Table 2.3. Combined environment analysis of variance of sucrose concentration ( $\%$ seed composition) for the University of Guelph soybean panel grown in four locations in Ontario Chatham and Ridgetown in 2015 and 2016 and St. Pauls and Woodstock from 2015 to $2017 \ldots .25$

Table 2.4. Correlations between sucrose concentration and agronomic traits in a diversity panel developed at the University of Guelph. St. Pauls and Woodstock locations were pooled across the 2015 and 2016 growing seasons, and St. Pauls and Woodstock were pooled across the 2017 growing season. Data represent the Pearson correlation coefficients.

Table 2.5. Correlations between sucrose concentration and agronomic traits in a diversity panel developed at the University of Guelph Ridgetown campus. Chatham and Ridgetown locations were pooled across the 2015 and 2016 growing seasons. Data represent the Pearson correlation coefficients 26

Table 2.6. Putative sucrose QTL identified through analysis in GAPIT in a 296 line diversity panel developed at the University of Guelph. The lines were grown at Chatham, St. Pauls, Ridgetown, and Woodstock, Ontario from 2015 to 2017. 30

Table 3.1. Haplotype groups based on output from Autohaplo. The first five haplotype groups comprise the common haplotype groups and the last three haplotype groups comprise the rare haplotype groups..... 40

Table 3.2. Haplotype groups A-H. The haplotype groups were based on a 282 line panel from the University of Guelph that was grown in Chatham and Ridgetown, Ontario in 2015 and 2016 and St. Pauls and Woodstock, Ontario from 2015 to 2017. Data represent the LSMEANS. 42

Table 4.1. Monthly daily maximum, minimum, daily mean temperatures, total precipitation and CHU estimates during the growing season for St. Pauls and Woodstock from 2015 to $2017 \ldots . . .53$

Table 4.2. Sucrose concentration for the University of Guelph panel in individual environments, combined years, combined locations and all environments. The lines were grown St. Pauls and Woodstock from 2015 to 2017. Data represent the minimum, maximum, mean and standard errors $(\alpha=0.05)$ .56

Table 4.3. Soybean genotype mean sucrose concentration ( \pm standard error) over six environments. Data represent the LSMEANS 


\section{List of Figures}

Figure 2.1. PCA of the 296 line panel. Each colour and symbol corresponds to a different point of origin for each line (AAFC, Agriculture and Agri-Food Canada; RCATEXP, Ridgetown campus experimental lines; RCATVAR, Ridgetown campus released cultivars; UGEXP, University of Guelph main campus experimental lines; UGVAR, University of Guelph main campus released cultivars; Historical, breeding program lines from 1900s-1970s; Other, Chinese introductions and G. soja lines).

Figure 2.2. GAPIT output of putative sucrose QTL for the University of Guelph germplasm consisting of 296 lines grown in St. Pauls, Ridgetown and Woodstock from 2015 to 2017. Chromosome 6 has the only putative QTL for sucrose concentration in this panel. 28

Figure 3.1. Haplotype groups determined based on a 282 line panel from the University of Guelph. Lines were grown in Ridgetown, Ontario in 2015 and 2016 and St. Pauls and Woodstock, Ontario from 2015 to 2017. Each haplotype is named A-H, with the exception of WT which corresponds to haplotype group A. The number of lines in each group is represented by the number beside the haplotype group. The green colour represents the major allele while the purple represents the minor allele at each position. Sucrose concentration represents the average phenotype per haplotype group

Figure 4.1 . Top $20 \%$ of genotypes as a function of sucrose concentration (\%) combined over six environments

Figure 4.2. Plot of mean sucrose concentration performance against CV in a 140 genotype soybean diversity panel. The experiment was grown at St. Pauls and Woodstock, Ontario, from 2015 to 2017.

Figure 4.3. GGE biplot for sucrose concentration (\%) of the seed of a 140 line panel of genotypes grown at two locations, St. Pauls and Woodstock, Ontario, over three years, 2015 to 2017 .......60 


\section{General Introduction}

With the increasing demand of soybean (Glycine max L. Merr) production for the soy-food industry, it is necessary to focus breeding efforts on traits such as sucrose concentration, which is key for the production of palatable food products. An increase in the number of food-grade soybean cultivars has been driven by constant demand (Shi et al. 2010). Many soy-food items, including soy-milk, tofu and miso products require an adequate amount of sucrose in order to ensure high taste quality (Taira 1990). Breeding for high-sucrose cultivars requires line diversity and allelic variation linked to genes involved in the sucrose biosynthesis pathway. A University of Guelph soybean diversity panel was developed to assess the level of variation within the program over decades of breeding. It was hypothesized that sucrose concentration in soybean seed is a quantitative trait governed by quantitative trait loci (QTL). Two-hundred and ninety-six genotypes were grown in four locations, Chatham, St. Pauls, Ridgetown and Woodstock, Ontario over three years, from 2015 to 2017. A genome-wide association study (GWAS) was implemented to assess sucrose concentration and identify QTL linked to sucrose concentration (Chapter 2). Haplotype frequencies were also studied to determine the rate at which alleles for sucrose concentration were fixed in the breeding program over the past 100 years (Chapter 3). Finally, a look at the genotypeby-environment interaction was explored to determine the effect of genotype, environment, and genotype-by-environment on sucrose concentration (Chapter 4).

This thesis provides an overview for increasing variation in sucrose concentration in soybean seed within the University of Guelph germplasm, a way to track the loss of alleles through breeding for other major traits, and an evaluation of environmental and genotype-by-environment effects on sucrose concentration (Chapter 4). 


\section{Chapter 1: Literature Review}

\subsection{Introduction}

Soybean (Glycine max L. Merr) is a major oilseed crop, produced for both human and animal consumption, and is grown world-wide (Sugano 2006). Soybean is used widely for its available oil and protein in the seed; however, both the food industry and the nutraceutical industries have become increasingly interested in using soybean for a variety of products (Hartman et al. 2011). Soybeans have been a staple in Asian cuisine for many centuries, however, the shift for soy-based products is slowly starting to gain popularity in North America (Shi et al. 2010). The increase in the production of soy-derived food products must be matched by breeding for key traits that are needed for high-quality products.

Global production of soybean is estimated at 335 million tonnes (FAOSTAT 2016). In 2016, Canada was responsible for the production of 6.6 million tonnes, with the majority of soybean production occurring in Ontario, Manitoba and Quebec (Statistics Canada 2017). This is an increase from 6.4 million tonnes in 2015 (Statistics Canada 2017). It is estimated that in 2017, Canada produced 7.7 million tonnes of soybean (Statistics Canada 2017). The increase in soybean production is an indicator of its economic importance in Canada.

Aside from being a prominent source of vegetable oil globally, soybean is used as the main ingredient in a number of soy-derived food products, including tofu, soymilk and natto. A number of agronomic traits are important for the development of food-grade cultivars; however, some traits have been overlooked in the past. One such trait is sucrose concentration, which plays an important role in the overall quality and taste of soy products. 
Sucrose concentration is the most prominent oligosaccharide in soybean. It is a major energy source for fermentation of natto and provides the sweetness necessary for palatable soy products including tofu and soymilk (Taira 1990).

Soybean production relies on plant breeding efforts for continued plant improvement in yield and seed composition. The overall goal is to provide plant breeders with a better understanding of what genes are responsible for the underlying variation for traits of interest, including sucrose concentration, which allows for their manipulation in the development of future cultivars.

\subsection{Soybean seed constituents}

While the majority of studies in soybean are focused on protein and oil content, there is an increasing demand for a better understanding of the genetic control of particular key traits, including sucrose concentration. Soybean seeds are largely made up of three components: $40 \%$ protein, 20\% oil, and 35\% carbohydrates (Hymowitz and Collins 1974; Hou et al. 2009). The carbohydrates component can be broken down into three major soluble sugars, sucrose, raffinose and stachyose (Kumar et al. 2010). The latter two sugars are galactosyl derivatives of sucrose (Kumar et al. 2010). Raffinose and stachyose are indigestible carbohydrates and are found in lower concentrations than sucrose in the seed (Kumar et al. 2010; Pazur et al. 1962). Normally, the ratio of the soluble sugars within the seed are 4:1:2 sucrose:raffinose:stachyose, respectively (Kumar et al. 2010; Pazur et al. 1962). These concentrations vary among cultivars, with sucrose concentration ranging anywhere from 1.5 to $10.2 \%$ (Hymowitz and Collins 1974; Hou et al. 2009). Therefore, an ideal food-grade cultivar would have increased concentrations of sucrose with decreased 
raffinose and stachyose concentrations in order to avoid digestion problems in humans and animals (Hou et al. 2009).

\subsection{Sucrose concentration in food-grade cultivars}

Sucrose concentration has a direct effect on the taste and nutritional value of soy-derived food products (Hou et al. 2009). Moreover, certain processes accompanied by soy-derived food products, including fermentation for tofu and soy milk, are directed by the soluble sugar content in the seed, as it provides energy for the process of fermentation (Hou et al. 2009). Therefore, the development of cultivars with desirable sucrose levels is crucial.

In North America, products such as soymilk require high levels of sucrose compared to those found in Japan, which is a direct reflection of the standard diet in North America. Presently, there are more than 50 food-grade soybean varieties being grown in Canada with sucrose content ranging from $4.9 \%$ to $8.4 \%$ (OSACC Report 2015). For each variety, specific food-grade quality traits must be met depending on the soy-food product for which they are used. The three major food products for which a high sucrose concentration is necessary are: tofu, soymilk and natto (Taira 1990; Kumar et al. 2010). For tofu quality, there must be a balance between protein and sugars (Soy Canada 2016). For miso quality, there must be high amounts of sugars and total carbohydrates, and for soymilk quality, there must be high amounts of sugars, especially sucrose (Soy Canada 2016). Therefore, depending on which food product each cultivar is used for, it is essential that sucrose concentration is able to be manipulated within such commercial cultivars.

The increase in production of these soyfoods is also reflective of their health benefits, which are attributed to compounds included in the soy-food that provide protection against heart disease, cancer, and a wide range of other diseases (Carter and Wilson 1998; Messina and Messina 
1991; Rao et al. 2002). Therefore, the increasing soy-derived food market emphasizes the economic potential of developing high-yielding, high sucrose soybean cultivars.

\subsection{Relationship of sucrose to other soybean traits}

Total sugar contents and sucrose contents were previously reported by Hymowitz et al. (1972) and Li et al. (2012) to be positively correlated with oil, and negatively correlated with protein, which also corroborated earlier work done by Carter and Hopper (1942). However, Wolf et al. (1982) reported the opposite, and stated that sucrose had a positive correlation with protein, and therefore, negative correlation with oil. Total sugar contents were also shown to be positively correlated with sucrose and raffinose, but negatively correlated to stachyose (Hymowitz et al. 1972; Li et al. 2012). Sucrose was shown to have a positive correlation with raffinose but not stachyose (Hymowitz et al. 1972; Li et al. 2012). Free sugar contents, which includes sucrose, was also shown to have a significant positive relationship with total isoflavone concentration, but a negative correlation with total group A and B soyasaponins and total soyasaponins (Kim et al. 2005).

\subsection{Environmental effects on sucrose content}

Environmental and genotype-by-environment effects have been observed for the accumulation of sucrose in developing soybean seeds (Rao et al. 2002). Sucrose concentration has been studied to determine the effect of temperature on the mean accumulation of sucrose. Kumar et al. (2010) grew seven soybean genotypes in three different locations to study the effect of weather conditions on sucrose content. The researchers found that sucrose content increased at lower temperatures, and noted a $35 \%$ decrease in sucrose accumulation with an increase in $6^{\circ} \mathrm{C}$ 
(Kumar et al. 2010). A previous study by Guo and Oosterhuis (1995) reported similar results, in that low temperature stress led to an increase in seed sucrose concentration in hydroponically grown soybeans.

\subsection{Measuring sucrose in the seed}

Sucrose concentration has previously been determined using high performance liquid chromatography (HPLC) or enzymatic methods using commercial kits that are widely available (Giannoccaro et al. 2008; Sato et al. 2012; Teixeira et al. 2012). More recently, near-infrared reflectance spectroscopy (NIRS) has been introduced as an alternative method for determining sucrose concentration in the seed. A study by Choung (2010) has shown that NIRS is a suitable means for detecting and recording sucrose concentration in soybean when compared to results obtained through HPLC. The use of NIRS for measuring agronomic traits other than oil and protein is beneficial for breeding programs who analyze a large number of lines per annum (Sato et al. 2012). NIRS does not require additional sample preparation, such as that needed for HPLC, making it an efficient tool for breeders (Sato et al. 2012).

\subsection{Genome-wide association studies}

Genome-wide association studies (GWAS) are a useful tool for identifying genomic regions that are tied to agronomic traits and are used to study complex traits, such as sucrose concentration (Contreras-Soto 2017; Korte and Farlow 2013; Sonah et al. 2015; Fang et al. 2017). GWAS explores statistical associations between SNP markers and traits of interest to determine which genomic loci are associated with specific traits (Contreras-Soto et al. 2017). The use of high-density markers and a diversity panel result in a higher mapping resolution than one would 
have if they were using a bi-parental cross population and conventional quantitative trait loci (QTL) mapping methods (Zhang et al. 2015). Identifying and determining causal genes for quantitative traits is a necessity for breeders, and implementing GWAS allows breeders to capture both major and minor allelic effects that would otherwise be missed (Zhang et al. 2015).

GWAS has shown to be an effective tool for breeders in many crops of economic and agronomic importance, including maize and rice (Huang et al. 2010; Li et al. 2013; Poland et al. 2011; Tian et al. 2011; Zhang et al. 2015). The ability for soybean breeders to predict parental lines that are high-yielding, and stable requires in-depth understanding of the link between phenotype and genotype (Korte and Farlow 2013). In order to fully understand traits of agronomic importance, there must be extensive knowledge regarding the loci that underlie phenotypes of interest, as well as the genetic components of major traits (Korte and Farlow 2013). Moreover, the use of GWAS to determine the available genetic diversity within their respective programs is key for the future of cultivar development.

\subsection{Sucrose QTL}

Previously, Hymowitz and Collins (1974) identified a large variation in total sugar, and sucrose contents from an evaluation of 195 soybean cultivars. Sucrose ranged from $3.0 \mathrm{~g} / 100 \mathrm{~g}$ seed to $10.2 \mathrm{~g} / 100 \mathrm{~g}$ seed. They also noted that there was a higher range of sucrose contents in Glycine max compared to Glycine soja, suggesting that sucrose and other sugars in soybean are able to be manipulated by breeders by using parental lines of varying concentrations.

Hou et al. (2009) extended this study, using 20 diverse soybean genotypes and measuring the total sugar variation using rapid extraction and quantification methods. To build on this, Openshaw and Hadley (1981) showed that there is a high probability of heritability of total sugar 
contents in soybean. This was further studied by Maughan et al. (2000), who calculated the broad sense heritability of sucrose concentration at 0.82 . Given this information, it is obvious that a better understanding of how to manipulate sucrose concentration in soybean is vital for the improvement of soybean cultivars for different food products.

Several studies have identified significant QTL for sucrose concentration. Maughan et al. (2000) was the first study in which 17 QTL (chromosomes 5, 7, 8, 13, 15, 19 and 20) were identified by means of restriction fragment length polymorphisms (RFLPs), single sequence repeats (SSRs), random amplified polymorphic DNA (RAPD), and morphological markers. Maughan et al. (2000) used a biparental cross between a high-sucrose G. max line V71-370 and a low-sucrose G. soja plant introduction (PI) 407162.

Kim et al. (2005) used recombinant inbred line (RIL) populations from a cross between 'Keunolkong' and 'Shinpaldalkong' to identify four QTL for sucrose concentration on chromosomes 2, 11 and 19. The major QTL, found on chromosome 19, accounted for $21.4 \%$ of the total variation in sucrose concentration. The remaining three QTL contributed minor effects. Kim et al. (2006) used another RIL population to identify two more QTL found on chromosomes 12 and 16, that were significant for sucrose concentration. Saghai Maroof and Buss (2008) reported a QTL located on chromosome 11 for sucrose concentration in V99-5089. Skoneczka et al. (2009) reported a QTL on chromosome 6 which explained $76 \%$ of the sucrose variation that was observed in the $\mathrm{F}_{2}$ populations derived from PI 87013 x PI 200508 and PI 243545 x PI 200508. Wang et al. (2014) reported three QTL for sucrose content on chromosomes 7, 11 and 20 using a cross between V99-5089 and V97-3000. The QTL reported on chromosome 11 corroborated earlier work done by Saghai Maroof and Buss (2008). Finally, Zeng et al. (2015) crossed a low sucrose line, MFS553 with a high sucrose PI 243545, and reported three novel QTL for sucrose concentration. The 
QTL were mapped to chromosomes 5, 9 and 16 and accounted for 46,10 and $8 \%$ of the variation in sucrose, respectively.

\subsection{Allele mining}

Progress in the area of plant breeding is highly dependent on the availability of genetic variation that is currently in the breeding program. Breeding for traits of interest allows for the development of cultivars, which is necessary for growing breeding programs. However, genetic variation is lost after each round of selection (Gur and Zamir 2004; Ladizinsky 1998).

A lot of available genetic material can be found in wild relatives or land races, many of which have been preserved in gene banks around the world (Chan 2005; Kumar et al. 2010; Mardis 2008). Researchers have isolated alleles and inserted them into crops of agronomic importance, which has demonstrated that certain allele expression shifts dramatically when it is introgressed into its domesticated relative (Kumar et al. 2010). Hence, the available germplasm needs to be reevaluated for potentially useful genetic variation that can be used.

The use of gene banks have also become a major resource for genetic and genomic sequence data. Sequence data is highly useful when integrating new genetic material into a breeding program because breeders can isolate potentially important alleles related to traits they are interested in (Kumar et al. 2010; Latha et al. 2004). Alleles can be isolated to increase yield, quality, provide biotic and abiotic stress resistance, and increased nutrient use efficiency, among others (Kumar et al. 2010). This process is termed allele mining, and is an incredibly useful tool for breeders looking to integrate new genetic material into their existing germplasm. Identifying allelic variants is useful to both the gene bank for conservation purposes, but also to the breeder for determining novel alleles for trait improvement. 


\subsection{Hypotheses and Objectives}

Hypotheses:

I. Sucrose concentration in soybean seed is a quantitative trait that is governed by quantitative trait loci (QTL).

II. Allelic diversity for sucrose concentration has decreased significantly after selection for other soybean traits including yield, protein and oil.

III. A significant genotype-by-environment (GE) interaction exists for seed sucrose concentration.

Objectives:

In this thesis, a diversity panel of 296 genotypes from the University of Guelph main campus, University of Guelph Ridgetown campus, Agriculture and Agri-Food Canada and Chinese PI's was used with the following objectives to: (1) Determine the variation for sucrose concentration in 296 genotypes representing germplasm from the University of Guelph (2) Detect QTL associated with sucrose concentration using marker data. (3) Determine if alleles have been fixed for genes in the sucrose biosynthesis pathway within the germplasm (4) Determine if there is a significant genotype, environment or genotype-by-environment interaction effects on soybean seed sucrose concentrations. 


\section{Chapter 2: Candidate QTL for sucrose concentration in soybean seed}

\subsection{Abstract}

Soybean (Glycine max L. Merr) is largest oilseed crop in the world, which is grown for oil extraction, feed as well as a number of soy food products. Understanding the genetic control of specific traits in soybean is required for achieving plant breeding objectives. Sucrose concentration is becoming an increasingly important trait for the production of soy food products. The objective of this chapter was to identify quantitative trait loci (QTL) associated with sucrose concentration in soybean seed using a diversity panel. Analysis of molecular data of 296 soybean genotypes grown in four locations, Chatham, Ridgetown, St. Pauls and Woodstock, Ontario from 2015 to 2017. Sucrose concentration was measured using a near-infrared reflectance spectrometer. QTL analysis was performed using genotyping-by-sequencing (GBS) data analyzed in both TASSEL and GAPIT. A putative QTL was identified on chromosome 6. A significant positive correlation was observed between sucrose concentration and oil accumulation in the seed. Improved understanding of the genes involved in sucrose biosynthesis will allow for its manipulation in future soybean cultivars. 


\subsection{Introduction}

Soybean (Glycine max L. Merr.) is an important oilseed crop around the world (Kim et al. 2006). Although the majority of soybean production is outside of Asia, soybean is an important part of Asian cuisine (Rao et al. 2002). With the current increase in global population, the demand for food-grade soybean production has been increasing steadily, both nationally and internationally (Rao et al. 2002). In order to fulfill this demand, the development of new food-grade cultivars is necessary.

Successful food-grade cultivars are chosen based on physical traits, chemical traits and processing quality of the seed (Brar and Carter 1993, Rao et al. 2002). Sucrose concentration is a notable compositional trait that must be selected for, especially for particular food products in order to allow for the steady release of commercial cultivars. Soy-derived food products consist of a number of items including tofu, soymilk, soybean flour, and fermented products including soy sauce, miso and natto (Taira 1990).

Until present, there has been little work done on sucrose concentration in soybean breeding and research, because there is a need to focus on other agronomic and compositional traits such as yield, oil, protein, pathogen resistance, etc. The research that has been published on sucrose concentration has generally focused on quantitative trait loci (QTL) discovery using biparental populations. However, there has been no literature reporting on the detection of putative QTL using genome wide-association studies (GWAS) for sucrose concentration in the seed using a diversity panel. Given this, it was of interest to determine if GWAS was a suitable method for putative QTL detection for sucrose concentration in the seed.

QTL are genomic regions that are highly associated with quantitative traits, such as sucrose concentration. Determining QTL that are linked to traits of interest is key for breeders looking to 
develop successful cultivars. One way of determining if there are any putative QTL in a diversity panel is to make use of GWAS. GWAS is a useful tool for analyzing complex traits with a larger scope than traditional QTL identification strategies (Korte and Farlow 2013; Fang et al. 2017). Unlike biparental cross populations, the use of GWAS and a diversity panel captures allelic diversity and genetic background effects that may not have been uncovered otherwise (Heffner, Sorrells, Jannink 2009). Moreover, the use of GWAS allows breeders to detect both small and large chromosomal regions associated with traits of interest and provides them with estimates regarding the size and direction of allelic effects (Contreras-Soto et al. 2017; Abdel-Shafy et al. 2014).

Previously, several studies have identified significant QTL for sucrose concentration. Maughan et al. (2000) was the first study in which 17 QTL (chromosomes 5, 7, 8, 13, 15, 19 and 20) were identified. Later, Kim et al. (2005) used RIL populations from a cross between 'Keunolkong' and 'Shinpaldalkong' and found four QTL for sucrose concentration on chromosomes 2, 11 and 19. The major QTL on chromosome 19 accounted for $21.4 \%$ of the total variation in sucrose concentration. Skoneczka et al. (2009) used $F_{2}$ derived populations from PI 87013 x PI 200508 and PI 243545 x PI 200508 and identified a QTL on chromosome 6 which explained $76 \%$ of the sucrose variation. Finally, Zeng et al. (2015) crossed MFS-553 with PI 243545 and identified three novel QTL for sucrose concentration. The QTL were found on chromosomes 5, 9 and 16, respectively, and accounted for 46, 10 and $8 \%$ of the variation in sucrose, respectively.

The objective of this study was to characterize the University of Guelph diversity panel and determine if there were any significant QTL linked to sucrose concentration in the seed. To ensure diversity within the panel, lines from University of Guelph experimental and released 
cultivars, University of Guelph-Ridgetown experimental and released cultivars, AAFC cultivars, and Chinese germplasm were used. Putative QTL can be used in the future in order to develop and release food-grade cultivars for the North American market.

\subsection{Materials and methods}

\subsubsection{Plant materials and experimental design}

A diversity panel was developed, consisting of 296 lines from the University of Guelph, main campus experimental and released cultivars, the University of Guelph, Ridgetown campus experimental and released cultivars, Agriculture and Agri-Foods Canada cultivars, historical cultivars dating back to the early 1900s and Chinese plant introduction lines. A principal component analysis (PCA) was constructed using TASSEL 5.0 (Bradbury et al. 2007) and graphed using Gnumeric (Gnome Project 2017).

The diversity panel and checks were grown at four southern Ontario field sites, Chatham and Ridgetown, Ontario in 2015 and 2016 and the Woodstock Research Station and the Hart farm in St. Pauls during the 2015, 2016 and 2017 growing seasons. The Woodstock Research Station is located at $43^{\circ} 08^{\prime} 44.8^{\prime} \mathrm{N} 80^{\circ} 47^{\prime} 02.5^{\prime \prime} \mathrm{W}$. The St. Pauls field trial is located at $43^{\circ} 19^{\prime} 53.5^{\prime \prime} \mathrm{N}$ $81^{\circ} 08^{\prime} 06.7^{\prime \prime} \mathrm{W}$. The Chatham field is located at $42^{\circ} 20^{\prime} 12.7^{\prime \prime} \mathrm{N} 82^{\circ} 15^{\prime} 21.8^{\prime \prime} \mathrm{W}$. The Ridgetown field is located at $42^{\circ} 26^{\prime} 43.6^{\prime \prime} \mathrm{N} 81^{\circ} 52^{\prime} 58.7^{\prime}$ W. In 2015, the Woodstock site was planted on June $5^{\text {th }}$, the St. Pauls site was planted on May $21^{\text {st }}$, the Ridgetown site was planted on May $13^{\text {th }}$ and the Chatham field was planted on May $25^{\text {th }}$. In 2016 , the Woodstock site was planted on June $8^{\text {th }}$, the

St. Pauls site was planted on May $20^{\text {th }}$, the Ridgetown site was planted on May $27^{\text {th }}$ and the Chatham site was planted on May $20^{\text {th }}$. In 2017, the Woodstock site was planted on June $8^{\text {th }}$ and 
the St. Pauls site was planted on May $20^{\text {th }}$. Plots were planted as 4 rows, $5 \mathrm{~m}$ long and $1.6 \mathrm{~m}$ wide, with $42 \mathrm{~cm}$ row spacing and $45 \mathrm{~cm}$ between plots.

The experimental design was set up as a nearest-neighbour randomized complete block design (RCBD) with two replications at each site. The plots at each site were managed using conventional standard tillage, pest, and weed management applications. Field notes were taken for maturity twice a growing season, in order to classify the phenotypic differences in the diversity panel. Each location was harvested when every plot had reached full maturity.

\subsubsection{Sucrose concentration data collection}

Sucrose concentration was measured for each genotype grown in the field. A Perten DA 7250 analyzer (Springfield, USA) was used to accurately measure the concentration of sucrose in the seed. Factory calibration settings were used as they are set up to accurately measure sucrose (Choung 2010). The Perten DA 7250 analyzer uses whole soybean seeds to measure seed composition traits. Prior to analyzing the seeds with the near-infrared reflectance (NIR) analyzer, seeds were cleaned and the off-types were removed in order to ensure accurate results. One hundred seed weight was taken and recorded, as well as hilum colour. Maturity notes were also taken at each location once the lines reached full maturity (R8 stage) (Fehr et al. 1971).

Post-harvest seeds were kept in cold storage at the Elora Research Station in Elora, Ontario, for one month. Five hundred seeds per plot were analyzed for sucrose concentration and organized into a master file in Microsoft Excel. After exporting the NIR values to Microsoft Excel, it was noted that the NIR was unable to give accurate results for certain genotypes due to seed coat colour, or other confounding factors. The values appeared as negative values or extremely low values because the NIR uses reflectance, and therefore cannot accurately measure seeds with a dark seed 
coat colour. The lines that were removed are shown in Table 2.1 and were also removed from further GWAS analysis.

\subsubsection{Statistical analyses}

Analyses of variance (ANOVA) of sucrose concentration within the test locations was partitioned into fixed effects and random effects. Genotype was used as the fixed effect and block was used as the random effect using PROC GLIMMIX procedure from Statistical Analysis Systems (SAS) version 9.4 (SAS Institute Inc., Cary, NC, USA) for a RCBD. The PROC GLIMMIX procedure is a generalized linear mixed model that assumes normal random effects (SAS Institute Inc., Cay, NC, UAS). Radial smoothing was performed in SAS 9.4 (SAS Institute Inc., Cary, NC, USA) to adjust for spatial variation for sucrose concentration. The Shapiro-Wilk test (Shapiro and Wilk 1965) was used to visualize the distribution of the residuals using the PROC UNIVARIATE procedure. The PROC PLOT procedure was used to create a normality of residual distribution in SAS version 9.4 (SAS Institute Inc., Cary, NC, USA).

Combined analyses of variance were conducted over ten environments (Chatham, St. Pauls, Ridgetown and Woodstock) from 2015 to 2017 using PROC GLIMMIX procedure, with genotype as a fixed effect and environment as a random effect. Ridgetown and Chatham lines were grown in 2015 and 2016, whereas St. Pauls and Woodstock locations were grown from 2015 to 2017. Least square means (LSMEANS) were calculated using PROC GLIMMIX procedure across single locations and combined location analyses. Pearson's correlation coefficients were calculated using the PROC CORR procedure performed between sucrose concentration LSMEANS and protein, yield and oil LSMEANS to determine any linear correlation. 


\subsubsection{Genotyping-by-sequencing (GBS)}

Sequencing was carried out for 296 genotypes in the University of Guelph and University of Guelph Ridgetown germplasm panel. DNA extraction was performed using the Qiagen DNeasy 96 Plant kit (Toronto, Canada) following the manufacturer's protocol. Single nucleotide polymorphism (SNP) genotyping was performed using a genotyping-by-sequencing (GBS) approach (Elshire et al. 2011). Two GBS libraries were designed following ApeKI and MspI/PstI digestion (Elshire et al. 2011; Mascher et al. 2014; Sonah et al. 2013) at the Plateforme d'analyses génomiques Institut de Biologie Intégrative et des Systèmes (IBIS), at the Université Laval in Quebec City, QC, Canada. Single-end sequencing of multiplex GBS libraries (one 96-plex GBS library per sequencing lane or chip) was performed on an Illumina HiSeq 2000 at the McGill University-Génome Québec Innovation Center in Montreal, QC, Canada, and on an Ion Proton machine at the Institut de Biologie Intégrative et des Systèmes (IBIS) at the Université Laval, Quebec, QC, Canada. A total of 150 million 100-bp reads were generated on the Illumina platform and 630 million 50- to $135-\mathrm{bp}$ reads were obtained on the Ion Torrent platform. Next-gen sequencing (NGS) sequence reads were processed through the Fast-GBS pipeline (Torkamaneh et al. 2017) and missing data imputation and integration was performed using BEAGLE v5 (Browning \& Browning 2007) previously described by Torkamaneh and Belzile (2015) and Torkamaneh et al. (2018).

\subsubsection{GWAS analysis}

The University of Guelph panel sequence data was imported in TASSEL 5.0 (Bradbury et al. 2007) and exported as a genotype hapmap file. A corresponding phenotype text file was also set up for each line in the genotype file with line name and respective LSMEAN estimates based 
on SAS output (SAS Institute Inc., Cary, NC, USA). GWAS analysis was performed per location per year, combined years and locations and an average per line over all years and locations.

GWAS analyses were performed using the Genomic Association and Prediction Integrated Tool (GAPIT) (Lipka et al. 2012). Three improved mixed linear models (MLM) (Yu et al. 2006), multi-locus mixed-model (MLMM) (Segura et al. 2012), enriched compressed MLM (ECMLM) (Li et al., 2014) and Settlement of MLM Under Progressively Exclusive Relationship (SUPER)

(Wang et al. 2014) were tested using either the covariate $\mathrm{P}$ from principal component analysis (PCA) with three principal components or the covariate Q, obtained from fastSTRUCTURE. Furthermore, two kinship matrices were calculated using either the VanRaden method (K) or the EMMA method $\left(\mathrm{K}^{*}\right)$ in order to determine relatedness among individuals (Kang et al. 2008; Torkamaneh and Belzile 2015). Each model that had both a kinship matrix (K or K*) and P or Q was tested (Li et al. 2014). The significance threshold was established using negative $\log (1 / \mathrm{p})$ (Wang et al. 2012). Overall, the model with $\mathrm{P}+\mathrm{K}^{*}$ proved to be the best fit for this analysis. The Q-Q plot was closest to a linear model, which was why these covariates were used.

\subsection{Results}

\subsubsection{Origin of lines comprising the diversity panel}

The various lines present in the University of Guelph soybean germplasm are displayed in Figure 2.1. The principal component analysis (PCA) shows the lines separated by their origin. Although the lines seem to be distributed throughout the PCA, there is a visible divide between the University of Guelph and University of Guelph-Ridgetown genotypes (Figure 2.1). 


\subsubsection{Phenotypic sucrose analysis of the diversity panel}

The minimums, maximums, means and standard errors for sucrose concentration in the University of Guelph panel at each location and year are presented in Table 2.2. The highest sucrose concentration in the panel at a single environment was observed at the St. Pauls location in 2015 with a mean and standard error of $7.38 \pm 0.066$. The lowest average sucrose concentration in a single environment was observed at the Woodstock location with a mean and standard error of $6.17 \pm 0.066$. The highest overall mean for sucrose across locations was in St. Pauls, with a phenotypic average of $7.16 \pm 0.036$. The lowest overall mean for sucrose across locations was in Ridgetown, with a phenotypic average of $6.35 \pm 0.035$. The combined environment mean was 6.75 \pm 0.021 . A combined analysis of variance is shown in Table 2.3, displaying a significant difference among the genotypes in the panel.

Correlations between sucrose concentration and other traits of agronomic importance were observed from pooled data by year (Table 2.2). Woodstock yield data for 2017 was dropped due to error. Analysis by year revealed significant negative relationships between sucrose and protein for Woodstock and Elora from 2015 to 2017 at the $p<0.001$ level. A positive relationship was observed between sucrose concentration and oil; however, this relationship was not significant. A significant positive relationship between sucrose concentration and yield was observed for Woodstock and Elora 2015, 2016 and 2017. Furthermore, earlier findings of soybean oil and protein having a strong negative correlation was corroborated here in Tables 2.4 and 2.5 (Hwang et al. 2014). A study with more locations and lines may improve the correlations that were found, especially those regarding the relationship between sucrose concentration and oil. 


\subsubsection{QTL associated with sucrose concentration}

GWAS was carried out using 40,307 SNP markers in GAPIT. FastSTRUCTURE was used to determine the number of populations within the panel. It was determined that there were 5 subpopulations within the University of Guelph and University of Guelph Ridgetown panel. One putative QTL was found to be associated with sucrose concentration in the seed, which was identified using GAPIT (Table 2.6). This QTL was found on chromosome 6 at position 15764100 $\left(\mathrm{r}^{2}=0.06, \mathrm{p}\right.$-value $\left.=1.37 \mathrm{E}-06\right)($ Figure 2.2$)$. Soybase (http://soybase.org) was used to determine if this QTL was close to any previously reported soybean genes that have any relationship with sucrose accumulation or synthesis. It was found that the soybean gene GAPC1, a glyceraldehyde dehydrogenase, is located in the same general area as the putative QTL and may be involved in overall seed sucrose concentration accumulation in the seed.

\subsection{Discussion}

A significant positive correlation was observed between sucrose concentration and oil at the Ridgetown location during the 2015 growing season (Table 2.3). Although this was the only environment that a significant positive correlation was found, it is hypothesized that there was a large environmental impact on the seed sucrose concentration across environments. A positive correlation between sucrose concentration and oil is valuable information for breeders looking to increase certain agronomic and seed traits. This has corroborated earlier published work regarding the relationship between sucrose concentration and oil (Carter and Hopper 1942; Hymowitz et al. 1972). There was also a significant negative relationship between sucrose concentration and protein, which corroborated earlier work done by Hymowitz et al. (1972) and Carter and Hopper (1942). More studies should be carried out in order to confirm these findings. 
One putative QTL, identified using GAPIT, was shown to be possibly associated with sucrose concentration in the seed (Table 2.4; Figure 2.2). This QTL is in the same region as the soybean GAPCl gene. The GAPC1 gene belongs to a class of enzymes called glyceraldehyde-3phosphate dehydrogenases $(G A P D H)$, which are key to catalyzing important steps in glycolysis. Previously, GAPC1 was shown to aid in plant cellular metabolism in Arabidopsis when exposed to both oxidative and water stresses (Hancock et al. 2005; Holtgrefe et al. 2008; Guo et al. 2012; Guo et al. 2014). However, Guo et al. (2014) have also done studies on the relationship between GAPC1 and seed oil accumulation in Arabidopsis. Perhaps with further work on this QTL and its relationship with sucrose concentration, this may be a beginning step for breeders looking to increase the amount of sucrose in seed for the purpose of developing new and improved foodgrade soybean cultivars.

To the best of our knowledge, there have been no previous studies that have analyzed genetic data for putative QTL for sucrose concentration using a GWAS and a diversity panel. Previous QTL studies for sucrose concentration have been carried out; however, they were done using biparental crosses. Therefore, further studies using GWAS and diversity panels should be carried out to identify other QTL that may be associated with sucrose concentration in the seed. Increasing the number and diversity may results in detection of additional QTL. New QTL would help breeders and their programs develop high sucrose food-grade cultivars that have the potential to be commercialized. Some of the possible reasons for not identifying more QTL are studied and discussed in the next chapter (Chapter 3).

In conclusion, a University of Guelph panel consisting of 296 soybean lines, University of Guelph experimental and released cultivars, University of Guelph-Ridgetown experimental and released cultivars, AAFC cultivars, and Chinese germplasm, were used to identify QTL for seed 
sucrose concentration. One putative QTL was found through the use of GWAS and GAPIT. Further genetic analyses must be carried out to validate this potential QTL associated with sucrose concentration on chromosome 6 . In addition, the negative correlation between protein and sucrose concentration allows for the inference that there is a positive correlation between oil and sucrose concentration. This was observed in Ridgetown 2015, in which the significant positive correlation between oil and sucrose was 0.95 . In order to elucidate the relationship between GAPC1 and sucrose concentration, further studies are needed. This could be a potential first step in determining a suitable way for breeders to improve overall seed sucrose concentration in the future. 
Table 2.1. Lines that were removed from the University of Guelph panel analysis due to insufficient growth in the field, or inaccurate readings from the DA7250 Perten NIR analyzer.

\begin{tabular}{ll}
\hline Genotype & Years dropped \\
\hline Manitoba Brown & 2015,2016 \\
SCNRIL 108 & 2016 \\
SCNRIL 195 & 2016 \\
SCNRIL 213 & 2016 \\
SCNRIL 215 & 2016 \\
SCNRIL 24 & 2016 \\
SCNRIL 51 & 2016 \\
SCNRIL57 & 2016 \\
SCNRIL 93 & 2016 \\
\hline
\end{tabular}


Table 2.2. Sucrose concentration for the University of Guelph panel in individual environments, combined years, combined locations and all environments. The lines were grown at Ridgetown in 2015 and 2016 and St. Pauls and Woodstock from 2015 to 2017.

\begin{tabular}{|c|c|c|c|}
\hline & \multicolumn{3}{|c|}{ Sucrose concentration (\% seed composition) } \\
\hline & Minimum & Maximum & Mean $(\mathrm{se})^{\mathrm{a}}$ \\
\hline \multicolumn{4}{|l|}{ Individual } \\
\hline \multicolumn{4}{|l|}{ Environment } \\
\hline Chatham 2015 & 5.37 & 8.35 & $6.94(0.049)$ \\
\hline Ridgetown 2015 & 5.09 & 7.99 & $6.53(0.049)$ \\
\hline St. Pauls 2015 & 5.17 & 8.87 & $7.38(0.066)$ \\
\hline Woodstock 2015 & 4.89 & 8.58 & $6.76(0.062)$ \\
\hline Chatham 2016 & 4.41 & 8.51 & $6.19(0.051)$ \\
\hline Ridgetown 2016 & 5.00 & 7.42 & $6.18(0.045)$ \\
\hline St. Pauls 2016 & 4.99 & 8.68 & $6.95(0.052)$ \\
\hline Woodstock 2016 & 5.22 & 8.96 & $7.21(0.061)$ \\
\hline St. Pauls 2017 & 5.29 & 9.31 & $7.19(0.065)$ \\
\hline Woodstock 2017 & 4.06 & 8.82 & $6.17(0.066)$ \\
\hline \multicolumn{4}{|l|}{ Location } \\
\hline Chatham & 4.41 & 8.51 & $6.57(0.042)$ \\
\hline Ridgetown & 5.00 & 7.99 & $6.35(0.035)$ \\
\hline St. Pauls & 4.99 & 9.31 & $7.16(0.036)$ \\
\hline Woodstock & 4.06 & 8.96 & $6.71(0.042)$ \\
\hline \multicolumn{4}{|l|}{ Year } \\
\hline 2015 & 4.89 & 8.87 & $6.90(0.031)$ \\
\hline 2016 & 4.41 & 8.96 & $6.66(0.032)$ \\
\hline 2017 & 4.06 & 9.31 & $6.68(0.054)$ \\
\hline All Environments & 4.06 & 9.31 & $6.75(0.021)$ \\
\hline
\end{tabular}

${ }^{a}$ Data represent the standard error $(\alpha=0.05)$. 
Table 2.3. Combined environment analysis of variance of sucrose concentration (\% seed composition) for the University of Guelph soybean panel grown in four locations in Ontario Chatham and Ridgetown in 2015 and 2016 and St. Pauls and Woodstock from 2015 to 2017.

\begin{tabular}{lcccc}
\hline Random effect & Estimate & Standard error $^{\mathrm{a}}$ & Z value & Pr $>$ Z \\
\hline Environment & 0.21 & 0.13 & 1.56 & 0.05 \\
Residual & 0.48 & 0.025 & 19.43 & $<.0001$ \\
& & & & \\
Fixed effect & Numerator df & Denominator df & F Value & $\operatorname{Pr}>\mathrm{F}$ \\
\hline Entry & 170 & 755 & 2.46 & $<.0001$ \\
\hline${ }^{a} \alpha=0.05$ & & & &
\end{tabular}


Table 2.4. Pearson's correlations between sucrose concentration and agronomic traits in a diversity panel developed at the University of Guelph. St. Pauls and Woodstock locations were pooled across the 2015 to 2017 growing seasons. Data represent the Pearson correlation coefficients.

\begin{tabular}{cclll}
\hline Environment & Trait & Oil & Protein & Yield \\
\hline 2015 & & 0.07 & $-0.66^{* * *}$ & $0.41^{* * *}$ \\
2016 & Sucrose & -0.04 & $-0.55^{* * *}$ & $0.25^{* * *}$ \\
2017 & & $-0.26^{* * *}$ & $-0.31^{* * *}$ & $0.15^{*}$ \\
2015 & & & $-0.66^{* * *}$ & 0.03 \\
2016 & Oil & & $-0.67^{* * *}$ & $0.14^{* *}$ \\
2017 & & & $-0.51^{* * *}$ & 0.06 \\
\hline 2015 & & & & $-0.36^{* * *}$ \\
2016 & Protein & & & $-0.20^{* *}$ \\
2017 & & & & -0.05 \\
\hline
\end{tabular}

* Significant at $\mathrm{p}<0.05 .{ }^{*}$ Significant at $\mathrm{p}<0.01 .{ }^{* * *}$ Significant at $\mathrm{p}<0.001$.

Table 2.5. Pearson's correlations between sucrose concentration and agronomic traits in a diversity panel developed at the University of Guelph Ridgetown campus. Chatham and Ridgetown locations were pooled across the 2015 and 2016 growing seasons. Data represent the Pearson correlation coefficients.

\begin{tabular}{ccccc}
\hline Environment & Trait & Oil & Protein & Yield \\
\hline 2015 & Sucrose & $0.95^{* * *}$ & $-0.67^{* * *}$ & $-0.22^{* * *}$ \\
2016 & & -0.09 & $-0.45^{* * *}$ & $-0.21^{* *}$ \\
2015 & Oil & & $-0.58^{* * *}$ & $-0.28^{* * *}$ \\
2016 & & & $-0.58^{* * *}$ & -0.02 \\
2015 & Protein & & & $0.34^{* * *}$ \\
2016 & & & & $-0.26^{* * *}$ \\
\hline
\end{tabular}

* Significant at $\mathrm{p}<0.05 .{ }^{* *}$ Significant at $\mathrm{p}<0.01 .{ }^{* * *}$ Significant at $\mathrm{p}<0.001$. 


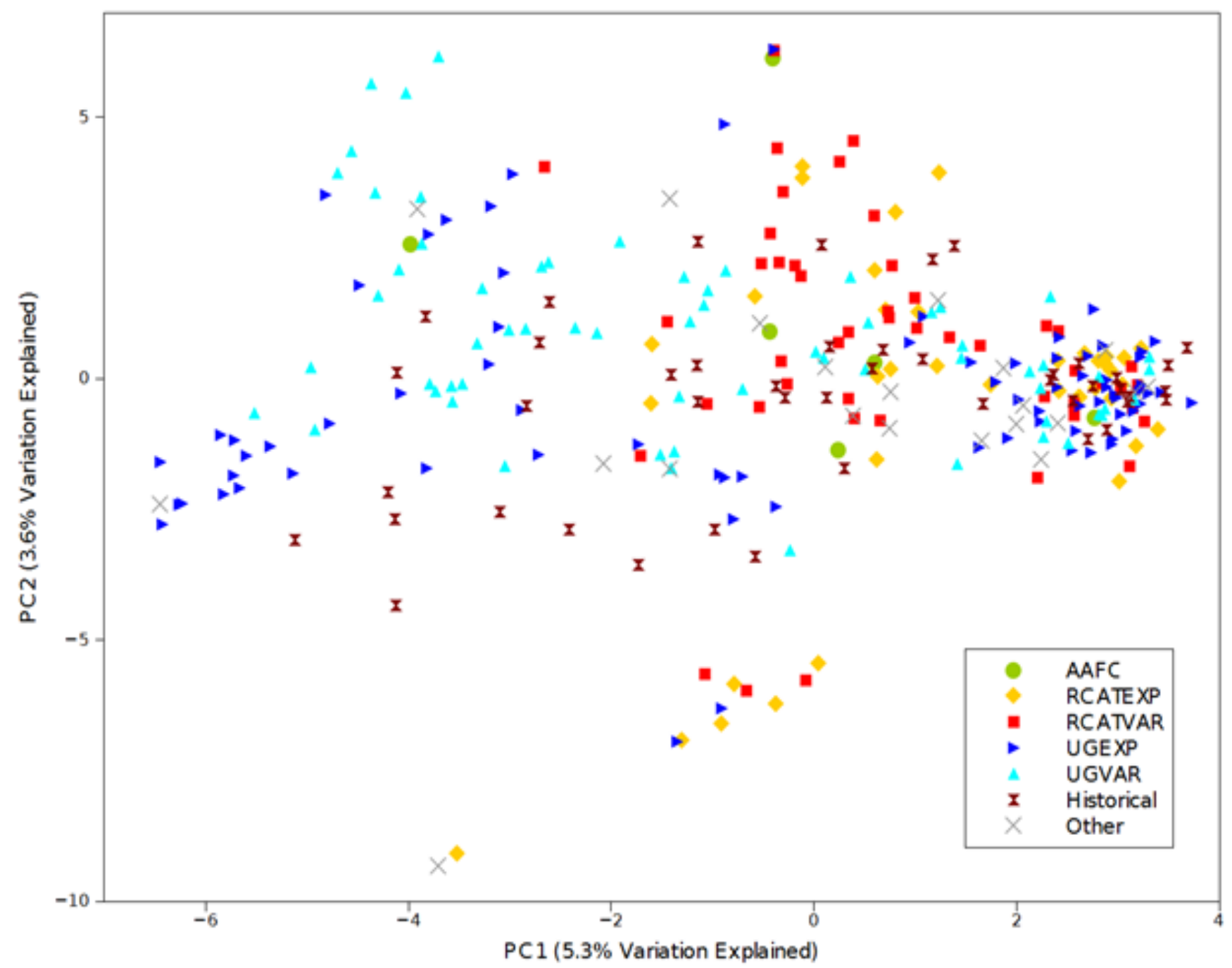

Figure 2.1. A principal component analysis (PCA) of the 296 lines that comprise the University of Guelph soybean panel. Each colour and symbol corresponds to a different point of origin for each line, where AAFC is Agriculture and Agri-Food Canada, RCATEXP is Ridgetown campus experimental lines, RCATVAR is Ridgetown campus released cultivars, UGEXP are University of Guelph main campus experimental lines, UGVAR are University of Guelph main campus released cultivars, Historical lines refer to lines used for breeding program development from 1900s-1970s, and Other refers to plant introductions from China, and $G$. soja lines. 


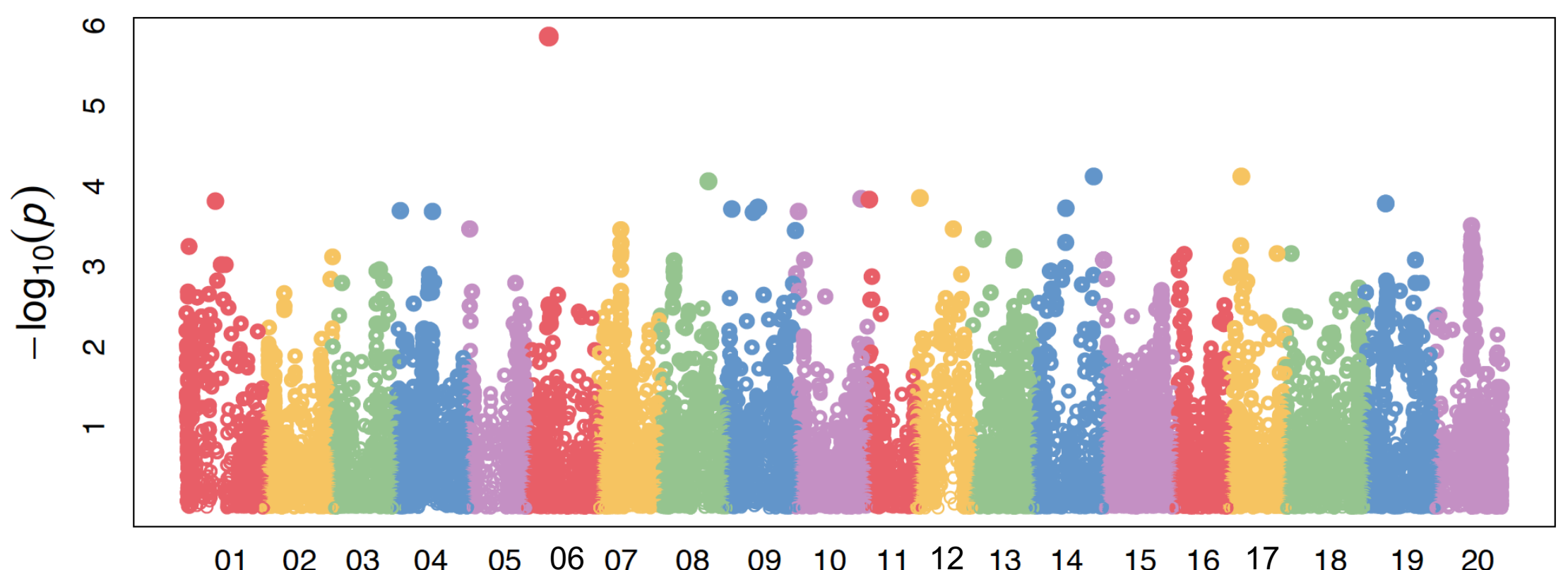

Figure 2.2. GAPIT output of putative sucrose QTL for the University of Guelph germplasm consisting of 296 lines grown in St. Pauls, Ridgetown and Woodstock from 2015 to 2017. Chromosome 6 has the only putative QTL for sucrose concentration in this panel. 
Table 2.6. Putative sucrose QTL identified through analysis in GAPIT in a 296 line diversity panel developed at the University of Guelph. The lines were grown at Chatham, St. Pauls, Ridgetown, and Woodstock, Ontario from 2015 to 2017.

\begin{tabular}{lllll}
\hline Chromosome & Position & maf & $\mathrm{R}^{2}(\%)$ & P-value \\
\hline 6 & 15764100 & 0.05 & 0.06 & $1.37 \mathrm{E}-06$
\end{tabular}




\section{Chapter 3: Allelic Diversity for Sucrose Content in the Soybean Seed}

\subsection{Abstract}

Soybean (Glycine max (L.) Merr) is a crop of global importance for both human and animal consumption. It was domesticated more than 3000 years ago in China, and has since lost the available some of its genetic variability as a result of decades of breeding. In order to improve and develop new cultivars, it is critical for breeders to know the genetic availability present in their program germplasm. Two hundred and eighty-two genotypes were grown in four Southern Ontario field locations from 2015 to 2017. Sucrose concentration was determined using a NIR analyzer. Haplotype groups were identified for the GAPC1 gene, a previously identified QTL for sucrose concentration. Allele fixation in the program was also used to determine which genotypes were more variable than others. This information will facilitate the breeders' efforts to increase the overall genetic variability for sucrose concentration and develop new and improved high-sucrose soybean cultivars suitable for the soy food industry.

\subsection{Introduction}

Soybean (Glycine max (L.) Merr) is a crop of global importance for both human and animal consumption. It is used largely as a source of protein meal and vegetable oil, but also has a number of industrial uses, such as biofuels (Hartman et al. 2011; Qiu et al. 2013). Soybean has been a staple in Asian cuisine for centuries but over time has slowly integrated into the European and North American food markets. Soy-derived food products like tofu, soymilk, tempeh, natto, sprouts and many others are widely available for human consumption around the world. Soyderived products provide the same amount of protein as food from animal sources; however, they have lower amounts of saturated fat and no cholesterol, making them an ideal health food (Qiu et 
al. 2013; Young 1991). These reasons, coupled with many others, have allowed for the growth of the food-grade soybean market worldwide.

The domestication of soybean (Glycine $\max$ (L.) Merr) occurred in China more than 3000 years ago (Fukuda 1933; Hymowitz 1970; Hymowitz and Newell 1981; Vavilov 1951). The movement of soybean from China to Japan, Indonesia, Philippines and Vietnam occurred by the 16 ${ }^{\text {th }}$ century A.D. (Hymowitz and Newell 1980; Qiu et al. 2013). Currently, soybean is produced in more than 60 countries around the world.

The largest collection of soybean accessions is housed in China, with $>23,000$ G. max accessions and $>7000 G$. soja accessions as its wild relative. The availability of these genotypes is important for advanced soybean lines that have to adapt to heterogeneous environments due to climate change (Qiu et al. 2013). Even with the wide genetic array of soybean accessions that is available to breeders around the world, $<1 \%$ of the lines have been used for breeding purposes (Qiu et al. 2013).

The next step for breeders is to find ways to integrate the soybean core collections that are found in gene banks into breeding materials. An important tool that is available to breeders is allele mining. Allele mining can be implemented after association analyses take place, like genome-wide association studies. GWAS allows breeders to discover genes controlling the natural variation of complex traits that is currently within their available germplasm (Huang et al. 2010, 2011; Qiu et al. 2013).

Accessions available in the gene bank are usually comprised of wild or landrace types, which house a vast amount of genetic variability that have been lost by selective processes over time. Domestication, selection and breeding deplete the available variability over time (Kumar et al. 2010; Tanksley and McCouch 1997). Using reference sets of wild and landrace soybean types 
would be a useful way to analyze naturally occurring allelic variation that has been lost through allele mining efforts (Kumar et al. 2010; Qiu et al. 2013). New variation will allow breeders to develop cultivars that possess previously occurring genetic variability for important agronomic traits.

The Autohaplo program was used to determine allelic diversity within the University of Guelph panel. This program was developed by Aurélie Tardivel and Marc-André Lemay of the Université Laval (personal communication). The program uses $\mathrm{R}$ to define gene-centered haplotypes of genes of interest, specifically, represent putative alleles of genes of interest based on the position of the gene in the genome. Autohaplo analyzes a genomic region surrounding the gene of interest and selects SNPs that would likely be useful for defining haplotypes. The program uses three major steps to choose the SNPs for haplotype definition: filtering, clustering and a final selection of markers.

The first step of the program, filtering, keeps SNPs that are located on the chromosome of the gene of interest that are at a maximal physical distance from the gene centre. The maximal distance is dependent on the LD pattern in the genomic region in which the gene is found; however, it is usually between $500 \mathrm{~kb}$ to $1 \mathrm{Mb}$. SNPs were filtered based on minor allele frequency (MAF); however, SNPs can also be filtered based on the proportion of heterozygosity, proportion of missing data or minor allele count.

The clustering step computes linkage disequilibrium (LD) between all pairs of markers that were left after the filtering step. The pairs are clustered to reduce the marker set to only those that are informative. All marker pairs that have a LD coefficient greater than the set threshold are clustered and one is kept under the assumption that all markers in a cluster provide the same information. 
The last step is the final selection step, which keeps the final informative markers in the region of interest. Markers that are located on different ends ( $3^{\prime}$ and $\left.5^{\prime}\right)$ of the gene centre and are in LD are kept for haplotype definition. It is assumed that markers that are in LD across the gene centre are in LD with polymorphisms located inside the gene sequence.

As stated in the previous chapter, the putative QTL that was found was in the same general region as a previously published GAPC1 gene. This gene belongs to a class of enzymes that are responsible for catalyzing reactions in glycolysis (Guo et al. 2014). A previous study by Guo et al. (2014) has shown that the presence of the GAPCl gene was correlated with higher overall seed oil accumulation. It has been shown that total sugar content and sucrose concentration were positively correlated with oil, and negatively correlated with protein (Carter and Hopper 1942; Hymowitz et al. 1972; Li et al. 2012). Therefore, there may be a connection between the presence of GAPC1 and overall seed sucrose accumulation.

The objective of this study was to characterize and analyze the allelic variation present for the GAPCl gene related to sucrose that is present in the University of Guelph panel. The improved knowledge of the allelic variation in the panel will allow for the integration of new variation which will ultimately lead to the development of enhanced sucrose food-grade cultivars for the agri-food sector.

\subsection{Materials and Methods}

\subsubsection{Plant materials and experimental design}

A diversity panel comprised of 296 lines from the University of Guelph main campus and the University of Guelph Ridgetown campus were used in this study as described in Chapter 2. 
The field experiments were set up as a nearest-neighbour RCBD with two replications in four locations, Chatham, St. Pauls, Ridgetown and Woodstock, Ontario.

\subsubsection{Sequence data}

Sequence data was obtained for all lines from Université Laval. FastGBS was used to develop genotyping-by-sequencing data which was used for analysis, as described in Chapter 2.

\subsubsection{Sucrose concentration data}

Sucrose data was obtained for all lines using the Perten DA 7250 analyzer as described in Chapter 2.

\subsubsection{Autohaplo}

There are five import files necessary to run the program, as described below. Chromosome number and size was obtained using Soybase version Glyma.Wm82.a2 (Gmax2.0) (http://soybase.org) and set up as an individual import file in tab-delimited text format. Each gene of interest has its own text file that contains the name of the gene, which chromosome it is located on and its position within that chromosome. An individual file was set up for GAPCl, the closest gene to the putative QTL that was described in Chapter 2. The genotype and corresponding phenotype files that were described in Chapter 2 were also used for Autohaplo. The last file that was used was a kinship file that was exported using TASSEL 5.0 as a diploid file for each line in the genotype file (Bradbury et al. 2007). Autohaplo re-filters the genotype file, in order to trim the number of markers. Each gene requires its own code depending on the respective file names; however, the genotype, phenotype, kinship, and chromosome files can remain the same. Certain 
lines were removed due to the program's inability to handle heterozygotes, leaving the final analysis with 282 lines.

\subsubsection{Statistical analyses}

All statistical analyses carried out were performed under the assumptions that are made for generalized linear mixed model, therefore, PROC GLIMMIX procedure was implemented. The assumptions that follow a linear mixed model were: (i) the error is normally distributed, (ii) the error variance is homogeneous, (iii) error is independent, and (iv) the independent variables exhibit a linear relationship when plotted against the dependent variable. These assumptions were verified using a number of statistical tests including a normality test, a test of heterogeneity, a test of linearity for fixed effects as well as a visual Q-Q plot of normal distribution.

Radial smoothing was performed in SAS 9.4 (SAS Institute Inc., Cary, NC, USA) to define the spatial distribution of the residuals for sucrose concentration. The Shapiro-Wilk test was used (Shapiro and Wilk 1965) in PROC UNIVARIATE procedure to look at the distribution of residuals, which also tested the assumption of normality in SAS version 9.4 (SAS Institute Inc., Cary, NC, USA).

Two hundred and eighty-two lines were used for statistical analysis after Autohaplo removed 14 lines due to heterozygosity. Boxplots were created using PROC GLIMMIX procedure in SAS version 9.4 (SAS Institute Inc., Cary, NC, USA) to represent differences in phenotype corresponding to each haplotype group. An ANOVA was carried out using PROC GLIMMIX procedure in SAS version 9.4 (SAS Institute Inc., Cary, NC, USA) to determine if the observed differences between haplotype definitions were statistically significant. Finally, Tukey's highly 
significant difference (HSD) test was also carried out in SAS version 9.4 (SAS Institute Inc., Cary, $\mathrm{NC}$, USA) to determine which haplotype groups were significantly different from one another.

\subsection{Results}

\subsubsection{Haplotype definition in the panel}

The University of Guelph panel was previously genotyped and phenotyped for all three years, 2015 to 2017 in all locations. Each genotype was used in the Autohaplo program, using the output from the GWAS described in Chapter 2. An initial genotype file with 40,307 SNPs was imported into Autohaplo to represent the sequence data for the 282 lines in the panel. This was needed to determine the allelic variation in these lines with regards to the GAPCl gene in soybean. The Autohaplo log output displayed that there were 8 distinct haplotype groups in the panel being: a wild type haplotype, four additional common haplotype groups and three rare haplotype groups (Figure 3.1). These groups were split up based on the number of lines allocated to each haplotype. Table 3.1 displays the full list of haplotypes and the corresponding number of lines that belong to each group. The alleles at each position for each haplotype group are shown in Figure 3.1.

\subsubsection{Phenotypic distribution based on haplotype group}

Each haplotype group was divided based on the lines that were allocated to each haplotype. The average of the LSMEANS of the lines were calculated to determine the phenotypic distribution of sucrose concentration by haplotype group (Table 3.2). Haplotype group A had major alleles at each position had the highest phenotypic mean for sucrose concentration, $7.34 \pm$ $0.20 \%$. The lowest haplotype group, G, had a phenotypic mean of $5.64 \pm 0.22 \%$. Statistical analysis using a means comparison showed that the difference in sucrose concentration between the 
haplotype groups is significant (Table 3.2). The analysis of variance of sucrose concentration showed that the main effect, haplotype group, was significant $(\operatorname{Pr}>\mathrm{F}<.0001$, Table 3.2). A Tukey multiple range test showed which haplotype groups were significantly different from one another. Statistical analysis showed that haplotype group is significant, with group A being significantly different than haplotype groups C, D, F and G. Haplotype group B was significantly different from group G. Haplotype group C was significantly different from both group A and G. Haplotype group D was significantly different than group A and group G. Haplotype group E was significantly different than group G. Haplotype group F was significantly different than group A. Haplotype group G was significantly different than groups A, B, D, E and H. Finally, haplotype group H was significantly different than group G. A summary is displayed in Table 3.2.

\subsection{Discussion}

With the increasing human population, the demand for new and improved crops is high (Tester and Langridge 2010). Soybean is one of the major crops of economic importance, and because of this, it is key that breeders continue to find ways to manipulate the genetic variation that is available to them to continue developing new cultivars with superior traits.

The sucrose concentrations that were recorded in this study are within the range of previously reported soybean sucrose studies (OSACC 2015 to 2017). Haplotype group A had the highest overall sucrose concentration mean, of $7.34 \pm 0.20 \%$ seed composition. Haplotype group $\mathrm{G}$ had the lowest overall sucrose concentration mean of $5.64 \pm 0.22 \%$ seed composition. Significant events of allele fixation were reported after genotype and phenotype analysis, with a total of 8 separate haplotype groups (Table 3.1). The two largest haplotype groups contained 135 and 100 lines from the University of Guelph panel, out of a total of 282 lines (Table 3.1). The large 
number of lines belonging to haplotype groups B and D respectively is reflective of the use of the same or similar parental cultivars over the years in the breeding program. In order to determine suitable parental cultivars going forward, the first step that breeders should explore is to complete a germplasm pedigree. By tracing back cultivars within the program, there is a potential to determine where and when a lot of the genetic variation for sucrose concentration was lost. The next step would be to characterize the available genetic variation for a range of agronomic and seed traits, in order to ensure that there is a suitable amount for sustained genetic improvement of crops over a long period of time (Harlan 1987; Tanksley and McCouch 1997). It is possible that the sucrose QTL was located in a region with a genomic selection signature related to adaptation to Ontario.

As with every breeding program, certain agronomic and seed traits are important for breeders, including yield, high protein and/or high oil (Shi et al. 2010). As breeders continue to select for traits of interest, the allelic variation for other traits is lost (Burt et al. 2011). Sucrose concentration has been a largely ignored seed trait; however, it plays an important role in soyderived food products, such as tofu, soymilk and natto, which only recently became a growing commodity in the North American food market (Taira 1990; Kumar et al. 2010). Hence, breeding for high sucrose lines has been negligible, which is supported by my study. In order to create suitable commercial cultivars, breeders will have to begin to find ways to increase the available genetic variation and, therefore, allelic variation that is available within their respective breeding program.

A great source of genetic variation from both wild and commercial crops are found in gene banks around the world (Tanksley and McCouch 1997). The plant introductions that are found in gene banks consist of exotic lines, that are closely related to crops of economic importance. With 
the advent of high-throughput sequencing and genotyping methods, it is easier for breeders now to genotype the exotic lines to determine which contain genes related to high yield and higher nutritional quality to add to their particular program.

In conclusion, 282 lines were used to determine the number of haplotype groups that are present within the University of Guelph soybean germplasm. Haplotype group A had the highest average sucrose concentration of $7.34 \%$ and consisted of Chinese plant introductions and experimental food-grade soybean lines. Haplotype group $G$ had the lowest average sucrose concentration at $5.64 \%$. Autohaplo was able to analyze and determine that there were 8 unique haplotype groups, consisting of anywhere from 1 line to 135 lines, which shows the total genetic variation that is present in the panel at the positions surrounding the GAPC1 gene. In order to increase the genetic variation present within the panel, exotic lines must be explored for the presence of allelic variation at these positions on chromosome 6 . Further studies should be carried out to determine and confirm the effect of GAPC1 on seed sucrose accumulation. 
Table 3.1. Haplotype groups based on output from Autohaplo. The first five haplotype groups comprise the common haplotype groups and the last three haplotype groups comprise the rare haplotype groups.

\begin{tabular}{lc}
\hline \multicolumn{1}{c}{ Haplotype Group } & No. of Lines \\
\hline Common & 7 \\
Wild Type (A) & 100 \\
B & 135 \\
D & 9 \\
G & 26 \\
H & \\
Rare & 1 \\
C & 3 \\
E & 3 \\
F & 1 \\
\hline
\end{tabular}




\section{Common}

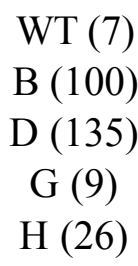

\begin{tabular}{|cccc|}
\hline $\mathrm{G}$ & $\mathrm{T}$ & $\mathrm{T}$ & $\mathrm{T}$ \\
\hline $\mathrm{G}$ & $\mathrm{T}$ & $\mathrm{G}$ & $\mathrm{T}$ \\
\hline $\mathrm{T}$ & $\mathrm{T}$ & $\mathrm{T}$ & $\mathrm{T}$ \\
\hline $\mathrm{G}$ & $\mathrm{C}$ & $\mathrm{G}$ & $\mathrm{T}$ \\
\hline $\mathrm{G}$ & $\mathrm{C}$ & $\mathrm{G}$ & $\mathrm{A}$ \\
\hline
\end{tabular}

7.34

6.85

6.67

5.64

6.82

\section{Rare}

C (1)

E (3)

F (1)

\begin{tabular}{|cccc|}
\hline $\mathrm{G}$ & $\mathrm{T}$ & $\mathrm{G}$ & $\mathrm{A}$ \\
\hline $\mathrm{T}$ & $\mathrm{T}$ & $\mathrm{T}$ & $\mathrm{A}$ \\
\hline $\mathrm{T}$ & $\mathrm{T}$ & $\mathrm{G}$ & $\mathrm{T}$ \\
\hline
\end{tabular}

Figure 3.1. Haplotype groups determined based on a 282 line panel from the University of Guelph. Lines were grown in Ridgetown, Ontario in 2015 and 2016 and St. Pauls and Woodstock, Ontario from 2015 to 2017. Each haplotype is named A-H, with the exception of WT which corresponds to haplotype group A. The number of lines in each group is represented by the number beside the haplotype group. The green colour represents the major allele while the purple represents the minor allele at each position. Sucrose concentration represents the average phenotype per haplotype group. 
Table 3.2. Haplotype groups A-H. The haplotype groups were based on a 282 line panel ${ }^{\text {a }}$ from the University of Guelph that was grown in Ridgetown, Ontario in 2015 and 2016 and St. Pauls and Woodstock, Ontario from 2015 to 2017. Data represent the combined environment LSMEANS.

\begin{tabular}{cccc}
\hline Haplotype Group & No. of Lines & $\begin{array}{c}\text { Sucrose concentration } \pm \\
\text { standard error }(\% \text { seed } \\
\text { composition })\end{array}$ & Letter Group $^{\mathrm{b}}$ \\
\hline Common & 7 & $7.34 \pm 0.20$ & $\mathrm{~A}$ \\
Wild Type (A) & 100 & $6.85 \pm 0.05$ & $\mathrm{AB}$ \\
B & 135 & $6.67 \pm 0.04$ & $\mathrm{~B}$ \\
D & 9 & $5.64 \pm 0.22$ & $\mathrm{C}$ \\
G & 26 & $6.82 \pm 0.10$ & $\mathrm{AB}$ \\
H & & & $\mathrm{BC}$ \\
Rare & 1 & $5.97 \pm 0.40$ & $\mathrm{AB}$ \\
C & 3 & $6.89 \pm 0.22$ & $\mathrm{BC}$ \\
E & 1 & $5.88 \pm 0.40$ & \\
F & 1 & 5
\end{tabular}

${ }^{\mathrm{a}}$ Lines were dropped from Autophaplo due to high levels of heterozygosity

bMean followed by the same letter are not significantly different according to Tukey's multiple range test $(\alpha=0.05)$. 


\section{Chapter 4: Genotype-by-Environment Effect on Sucrose Concentration}

\subsection{Abstract}

Soybean (Glycine max [L.] Merr.) is a widely grown oilseed crop around the world, increasing in popularity in the food sector. Sucrose concentration is an important seed trait that is necessary for the development of soy-derived food products. An understanding of sucrose concentration stability is necessary for the development of new and improved food-grade soybean cultivars. The objective of this chapter was to characterize sucrose concentration stability and the influence of genotype $(\mathrm{G})$, environment (E), and genotype-by-environment (GE) interaction. The study includes 140 University of Guelph germplasm grown in St. Pauls and Woodstock, Ontario, from 2015 to 2017. Significant E, G, and GE interaction effects were observed in the trial for sucrose concentration. G and GE were displayed using biplots, allowing for the visualization of cultivar sucrose concentration performance stability in individual environments. Of the tested genotypes, RCAT 0706, OAC 10-40C (DS143C0) and OAC 11-59C-Tof were identified as stable, high sucrose cultivars that would be ideal to use as parents when developing new high sucrose food-grade cultivars. The identification of stable, high sucrose cultivars suggests that it is possible to improve the current sucrose profiles that are available in the University of Guelph germplasm. 


\subsection{Introduction}

Soybean (Glycine max [L.] Merr.) is a widely grown oilseed crop around the world. It is used primarily for its oil and protein; however, sucrose and overall sugar content has become an increasingly important trait for breeders, especially for its use in soy-derived food products. Sucrose is one of three major carbohydrates found in soybean, in conjunction with stachyose and raffinose. Of these, sucrose is the most abundant, ranging from 1.5 to $10.2 \%$ of total dry matter (Hymowitz and Collins 1974). The focus on sucrose is directly related to its applicability to the food market. Sucrose concentration is important for food-grade cultivars because it adds to the sweetness of the food products that are made from soybean. Currently, a number of food-grade soybean cultivars are being grown in Canada, however, the future development of higher sucrose cultivars is dependent on a number of factors.

The accumulation of sucrose in soybean seed is a quantitative trait that is influenced by both genetic and environmental variables (Kumar et al. 2010). There is currently little work done looking at the genetic and environmental effects on sucrose concentration. Previous reports have demonstrated that environmental conditions including ambient temperature during seed development has been shown to be very influential on the growth and development of lupin beans (Górecki et al. 1996). Furthermore, it has been shown that temperature has an effect on overall sucrose concentration. Wolf et al. (1982) grew a soybean cultivar called Fiskeby V and determined that under ambient temperatures $\left(18 / 13^{\circ} \mathrm{C}\right)$, sucrose concentration was measured at $8.1 \%$; however, when temperatures rose to $\left(33 / 28^{\circ} \mathrm{C}\right)$, sucrose concentration was measured to be $3.6 \%$. Therefore, they reported a decrease in sucrose concentration of 56\% (Wolf et al. 1982).

An integral part of determining ideal genotypes is to understand how each genotype performs across a number of environments, which is termed stability. For many years, plant 
breeders have been using genotype, environment, and genotype-by-environment effects to study multi-environment trial (MET) data. The effect of each genotype, environment, and genotype-byenvironment must be understood in order to properly select superior genotypes, for example, those lines that do well across a variety of environments (Yan et al. 2007). Francis and Kannenberg (1978) described mean-CV stability analysis, in which trait performance is plotted as a function of the coefficient of variation (CV). Another such way to study these effects is to use GGE biplots, which allows breeders to visualize genotype performance across environments (Yan et al. 2000).

The first step in creating cultivars with higher overall sucrose concentration in the seed is to determine the effects of genotype, environment, and genotype-by-environment interaction on sucrose accumulation. Being able to determine the stability of available genotypes is of utmost importance for the development of improved cultivars. The objective of this chapter was to determine the environmental stability of sucrose concentration performance using the University of Guelph diversity panel consisting of 140 lines across multiple environments. By understanding the effect of environment on each of the lines in the panel, breeders will be able to effectively choose parental lines that will result in the development of stable, high sucrose food-grade soybean cultivars.

\subsection{Materials and Methods}

\subsubsection{Plant materials}

A panel comprised of 140 lines from the University of Guelph germplasm were used in this study as described in Chapter 2. Thirty lines were removed from analysis because of failed performance in the field. 


\subsubsection{Experimental design}

The lines were grown as a nearest-neighbour RCBD at two locations, with two replications at each site over three years, resulting in six environments as described in Chapter 2.

\subsubsection{Climate data}

Monthly and daily maximum, minimum and mean temperatures were collected from the Environment and Climate Change Canada National Climate Data and Information Archive for the Woodstock location (Environment and Climate Change Canada 2018); however the dataset was incomplete. The weather station for the Woodstock research station is located at $43^{\circ} 08^{\prime} 10.044^{\prime \prime} \mathrm{N}$ $80^{\circ} 46^{\prime} 14.040^{\prime \prime} \mathrm{W}$ with an elevation of $376 \mathrm{~m}$ (Climate ID 6142286 ). Alternative precipitation and crop heat unit (CHU) data was taken from Farmzone.com (Farmzone 2018), which houses data for a number of farming regions across Canada. Climactic data from Weather Innovations Consulting LP (https://www.weatherinnovations.com/) for Welburn, Ontario, was used for St. Pauls for 2015 to 2017. This data included all temperatures, precipitation and CHU data.

\subsubsection{Statistical analyses}

Analyses of variance (ANOVA) of sucrose concentration within the locations was partitioned into a fixed genotype effect and a random block effect using the PROC GLIMMIX procedure in Statistical Analysis Systems (SAS) version 9.4 (SAS Institute Inc., Cary, NC, USA) for a RCBD. Radial smoothing was used in SAS 9.4 (SAS Institute Inc., Cary, NC, USA) to adjust for spatial distribution errors for sucrose concentration. Residual distributions were analyzed using the Shapiro-Wilk test (Shapiro and Wilk 1965) using the PROC UNIVARIATE procedure, and normality was assessed using the PROC PLOT procedure (SAS Institute Inc., Cary, NC, USA). 
For the 140 line panel, a combined ANOVA was carried out for the six environments (St. Pauls and Woodstock, Ontario) from 2015 to 2017 using PROC GLIMMIX, with genotype, environment, and genotype-by-environment as fixed effects, and block(environment) as the random effect. Least square means (LSMEANS) were calculated using PROC GLIMMIX in each environment and combined across environments. Tukey's multiple range test was calculated using PROC GLIMMIX to determine the difference between lines across combined environments.

\subsubsection{Stability analyses}

Biplots using both $\mathrm{G}$ and GE sources of variation were used in this analysis, which is based on singular-value decomposition (SVD) (Yan et al. 2000). GGE biplots use Sites Regression (SREG) linear-bilinear (multiplicative) model (Cornelius et al. 1996). SREG was carried out using the PROC GLM procedure in SAS version 9.4 (SAS Institute Inc., Cary, NC, USA) with code developed at the CIMMYT Biometrics Group, kindly provided by Dr. J Crossa. The SREG code used single-location LSMEANS for the 140 line panel. The GGE biplot consists of the first two principal components (PC) of analysis, representing G and GE respectively. Superior lines are represented by large PC1 values (high yielding) and low PC2 values (stability) (Yan and Rajcan 2002). The length of environmental vectors is indicative of its performance, with longer vectors representing ideal environments for testing the genotypes in question. The length of the vector is indicative of the discriminative power of the environmental testing and the performance of the genotype in question in those environments (Yan et al. 2007). Furthermore, trait-stability performance was also analyzed using the mean-CV method as described by Francis and Kannenberg (1978). 


\subsection{Results}

\subsubsection{Environmental influence on sucrose concentration in the seed}

Monthly and yearly climactic data displayed variability in both temperature and precipitation over the growing season (Table 4.1), which may have contributed to the variability in sucrose concentration among environments. Sucrose concentration phenotypic means and maximum and minimum sucrose concentration values in individual environments, combined locations, combined years, and combined environments are provided in Table 4.2. The highest average sucrose concentration was St. Pauls in 2015 (7.38 \pm 0.066$)$ (Table 4.2). This corresponds to generally cooler mean temperatures and high precipitation. The lowest average sucrose concentration was at Woodstock in 2017 (6.17 \pm 0.066) (Table 4.2). This corresponds to the highest recorded average temperature, and a lower accumulated precipitation. The average CHU accumulation as 3414, 3422 and 3304 from 2015 to 2017, respectively (Table 4.1).

\subsubsection{Genotype, environment, and genotype-by-environment interaction variance analysis}

The combined analysis of variance of sucrose concentration data of the 140 line University of Guelph panel showed that the main effects of genotype, environment, and genotype-byenvironment interactions were significant $(p<0.0001$; Table 4.3). Significant variation was not present within blocks across environments, as shown in Table $4.3(\mathrm{p}=<0.067)$; however, significant variation was present across environments (Table 4.3). Individual means for each genotype across environments is displayed in Appendix I. Tukey's multiple range test was also carried out to determine the differences between lines, if any (Appendix I). A graphical representation of the top 20\% highest sucrose lines is displayed in Figure 4.1. 
A mean-CV analysis was also done on the 140 genotype diversity panel (Figure 4.2), which divided the genotypes into four quadrants. The genotypes that are present in quadrants II and IV had an above average $\mathrm{CV}$, meaning they had greater variability than those genotypes in quadrants I and III (Figure 4.2). Therefore, the genotypes that are present in quadrant I are the most desirable lines for breeders (Figure 4.2). Genotypes with a higher than average sucrose concentration and lower than average variation were RCAT 0706 and OAC 10-40C (DS143C0) (Figure 4.2).

\subsubsection{Site regression analysis and GGE biplots}

The panel was used to calculate the first and second principal components based on an environment-centered principal component analysis for GGE biplots, both of which were significant $(\mathrm{p}<0.001)$ for sucrose concentration (Table 4.5). The PC1 and PC2 for sucrose concentration accounted for $68 \%$ of the total variation (Table 4.5 ).

The GGE biplot for sucrose accounted for $68 \%$ of the $\mathrm{G}$ and GE interaction total variation (Figure 4.3). PC1 accounted for approximately 54\% of the variation and PC2 accounted for approximately 14\% (Figure 4.3). The correlation between PC1 and G was strong $(\mathrm{r}=0.99 ; \mathrm{p}<$ 0.0001; Figure 4.3), ensuring that the biplot is informative. Three separate groups of environments were present on the GGE biplot, Woodstock and St. Pauls 2015, Woodstock 2016 and 2017 and St. Pauls 2016 and 2017. There is a distinct segregation between Woodstock and St. Pauls 2015 and Woodstock and St. Pauls 2016 and 2017 (Figure 4.3).

Given the segregation of three groups of environments, there were also three genotypes that performed best in each of these groups of environments. Woodstock 2016 and 2017 grouped with the average genotype performance across environments (GMET), suggesting that the genotype that performed well in this environment would be the ideal genotype across all 
environments. OAC 10-40C (DS143C0) was the best performing genotype in St. Pauls 2016 and 2017. OAC 11-59C-Tof was the best performing line in St. Pauls and Woodstock 2015. RCAT 0706 was the best performing genotype in Woodstock 2016 and 2017, and is considered the most generally-adapted line across all environments. The best performing genotypes are found running perpendicularly to an environmental vector to the origin. Genotypes with a large PC1 value indicate high sucrose concentration, whereas a low PC2 value shows higher trait stability across the environments. Environments that have both high PC1 values but low PC2 values would be crucial for testing the genotypes available in the panel.

\subsection{Discussion}

The sucrose values that were reported in this study fall within the range of previous reports (http://www.gosoy.ca/osacc_fg_database.php). Significant differences in sucrose concentration values in $2015(7.17 \pm 0.061), 2016(6.99 \pm 0.062)$, and $2017(6.68 \pm 0.054)$ indicate that there is an environmental influence on sucrose accumulation in the seed (Table 4.2). It has been previously reported that sucrose accumulation is concentrated during plant development (Lichtner and Spanswick 1981). Given the difference in maturity among the 140 lines in the panel, there is a potential that the sucrose concentration in the seed was affected by maturity. It is also understood from previous reports that temperature also has an effect on sucrose accumulation (Guy et al. 1992; Wolf et al. 1981). Although poorly understood, Wolf et al. (1981) reported a significant decrease in sucrose accumulation with increasing temperature. Therefore, there are a number of environmental attributes that may have contributed to the varying sucrose levels in the lines grown over the years. Further studies are required to corroborate these findings. 
Plant breeders are interested in learning about the environmental and genotype-byenvironment effects, as it gives insight into the stability of genotypes in the available germplasm. Stability is important for plant breeders because a genotype's ability to do well across multiple environments is indicative of its performance as a parent. Due to fluctuations in the climate over years, it is important for breeders to continue to use stable genotypes for the development of improved lines. In the University of Guelph panel, a significant genotype-by-environment effect was found in the 140 line panel for sucrose concentration. Therefore, it is important to study the effects of environment on these lines further.

GGE biplots can be a useful tool for plant breeders because it allows them to visualize the performance of genotypes across environments (Yan et al. 2000). The association between the Woodstock 2016 and 2017 environmental vectors in the sucrose GGE biplot showed that trait stability was stronger in this location over two years compared to the 2015 year and the St. Pauls location (Figure 4.2). The relatively high PC1 and low PC2 values for Woodstock 2016 and 2017 indicated that they were more favourable environments to test the sucrose concentration of the 140 genotype panel. It is also apparent that the St. Pauls and Woodstock locations were more similar in 2015 than they were in either 2016 and 2017. The 2015 year for both locations has a high PC2 value, indicating high instability. The weather data for those years shows high amounts of precipitation and high average $\mathrm{CHU}$, which could have an effect on sucrose accumulation in the seed. There was also high weed pressure in the St. Pauls 2015 field, which may have contributed to the variable stability in the plots.

As stated earlier, GGE biplots are a useful tool for plant breeders, as they can use it to display the best genotypes available to them in their breeding program for particular traits of interest. Breeders look for high PC1 values, indicating high sucrose concentration, and low PC2 
values, indicating stability across multiple environments. Of the tested genotypes, RCAT 0706, OAC 10-40C (DS143C0) and OAC 11-59C-Tof were identified as stable, high sucrose cultivars that would be ideal parents for the development of new soybean food-grade cultivars.

In conclusion, 140 genotypes from the University of Guelph panel, which were grown in six environments, indicated that there were significant genotype, environment, and genotype-byenvironment interaction effects for sucrose concentration. Significant variation was observed between environment for sucrose concentration, which prompted the study to determine how these effects affected sucrose accumulation. Stable, high-sucrose genotypes were identified in this study, which may be important in the future development of high-sucrose food-grade lines. The relatively low stability, low-sucrose lines are also informative to breeders, especially when determining how to increase the available sucrose variation in a breeding program. 
Table 4.1. Monthly daily maximum, minimum, daily mean temperatures, total precipitation and CHU estimates during the growing season for St. Pauls and Woodstock from 2015 to 2017.

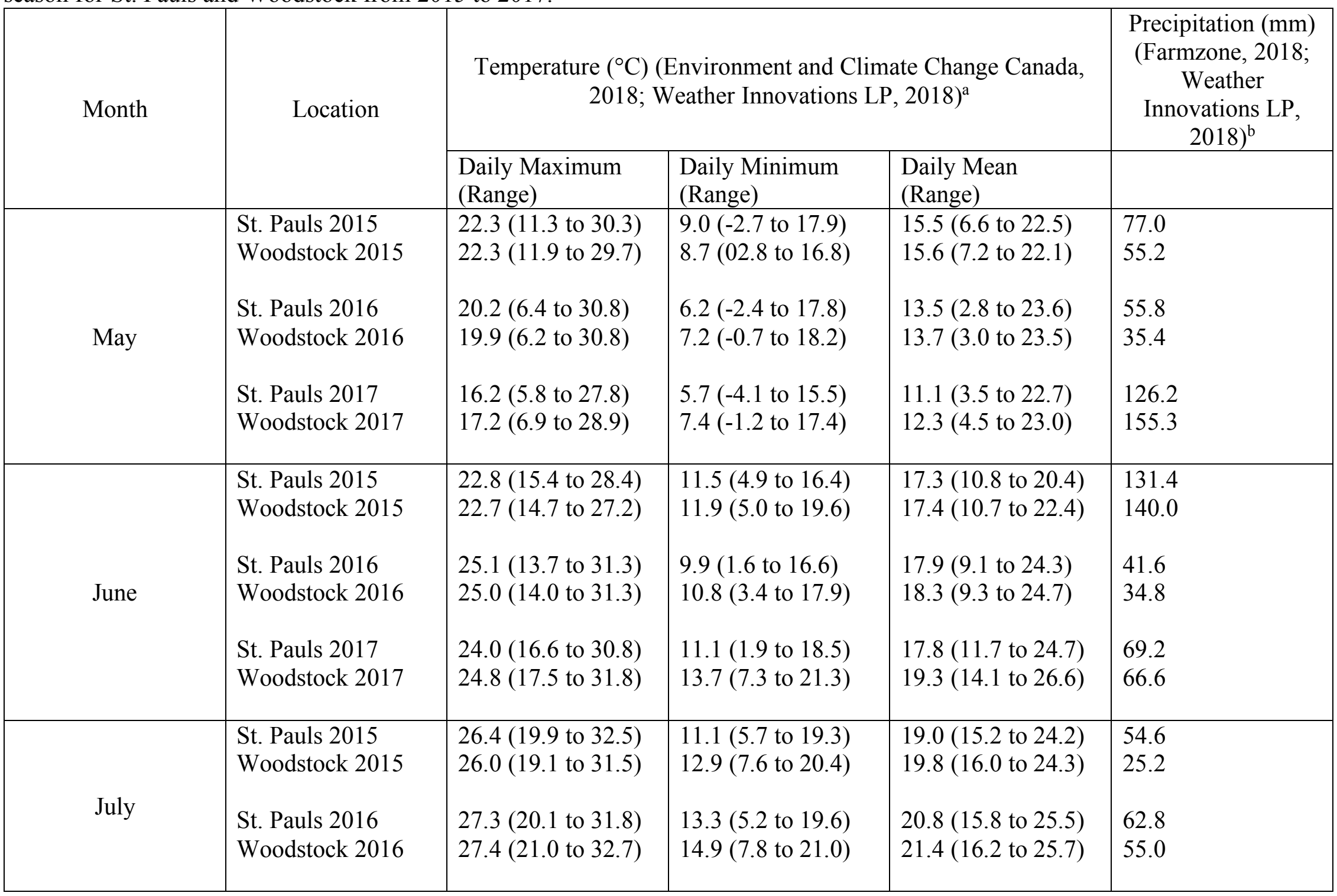




\begin{tabular}{|c|c|c|c|c|c|}
\hline & $\begin{array}{l}\text { St. Pauls } 2017 \\
\text { Woodstock } 2017\end{array}$ & $\begin{array}{l}26.4(18.6 \text { to } 30.3) \\
26.4(19.9 \text { to } 30.2)\end{array}$ & $\begin{array}{l}12.4(6.7 \text { to } 17.5) \\
15.6(12.120 .8)\end{array}$ & $\begin{array}{l}19.6(16.7 \text { to } 21.9) \\
21.0(17.8 \text { to } 24.3)\end{array}$ & $\begin{array}{l}87.8 \\
57.4\end{array}$ \\
\hline August & $\begin{array}{l}\text { St. Pauls } 2015 \\
\text { Woodstock } 2015 \\
\text { St. Pauls } 2016 \\
\text { Woodstock } 2016 \\
\text { St. Pauls } 2017 \\
\text { Woodstock } 2017\end{array}$ & $\begin{array}{l}25.2(17.9 \text { to } 30.7) \\
24.5(18.4 \text { to } 30.2) \\
27.6(22.7 \text { to } 33.2) \\
27.6(22.5 \text { to } 32.0) \\
25.0(19.6 \text { to } 30.6) \\
24.8(19.8 \text { to } 30.3)\end{array}$ & $\begin{array}{l}11.4(4.4 \text { to } 18.9) \\
12.9(6.7 \text { to } 19.0) \\
13.7(7.3 \text { to } 22.0) \\
15.4(10.1 \text { to } 21.7) \\
10.1(2.3 \text { to } 17.0) \\
13.1(6.5 \text { to } 18.1)\end{array}$ & $\begin{array}{l}18.2(13.7 \text { to } 24.0) \\
18.7(14.5 \text { to } 23.9) \\
20.7(15.9 \text { to } 25.6) \\
21.5(16.8 \text { to } 24.8) \\
17.8(12.2 \text { to } 22.2) \\
18.9(13.4 \text { to } 23)\end{array}$ & $\begin{array}{l}68.6 \\
50.0 \\
150.4 \\
198.6 \\
44.8 \\
42.4\end{array}$ \\
\hline September & $\begin{array}{l}\text { St. Pauls } 2015 \\
\text { Woodstock } 2015 \\
\text { St. Pauls } 2016 \\
\text { Woodstock } 2016 \\
\text { St. Pauls } 2017 \\
\text { Woodstock } 2017\end{array}$ & $\begin{array}{l}25.5(15.4 \text { to } 32.3) \\
24.5 \text { (15.4 to } 31.8) \\
24.0(16.7 \text { to } 31.8) \\
23.8(15.5 \text { to } 31.7) \\
24.3(16.1 \text { to } 33.2) \\
23.8 \text { (15.4 to } 32.2)\end{array}$ & $\begin{array}{l}10.4(2.4 \text { to } 19.3) \\
11.2(4.7 \text { to } 19.5) \\
9.9(3.8 \text { to } 20.0) \\
10.9(3.5 \text { to } 20.4) \\
8.7(0.6 \text { to } 16.6) \\
11.2(3.7 \text { to } 18.3)\end{array}$ & $\begin{array}{l}17.3(10.1 \text { to } 24.3) \\
17.6(10.8 \text { to } 24.6) \\
17.1(11.7 \text { to } 25.6) \\
17.2(11.8 \text { to } 24.9) \\
16.1(8.9 \text { to } 23.4) \\
17.3(9.6 \text { to } 24.8)\end{array}$ & $\begin{array}{l}79.0 \\
110.8 \\
36.4 \\
66.2 \\
66.6 \\
32.3\end{array}$ \\
\hline October & $\begin{array}{l}\text { St. Pauls } 2015 \\
\text { Woodstock } 2015 \\
\text { St. Pauls } 2016 \\
\text { Woodstock } 2016 \\
\text { St. Pauls } 2017 \\
\text { Woodstock } 2017\end{array}$ & $\begin{array}{l}14.8 \text { (4.2 to } 22.9) \\
14.0 \text { (4.2 to } 21.1) \\
15.5(3.9 \text { to } 25.3) \\
15.5(3.8 \text { to } 24.7) \\
17.2(4.3 \text { to } 25.7) \\
17.7 \text { (5.5 to } 25.6)\end{array}$ & $\begin{array}{l}2.6(-4.2 \text { to } 11.3) \\
3.7(-4.3 \text { to } 11.5) \\
4.8(-6.0 \text { to } 16.1) \\
5.0(-4.9 \text { to } 16.1) \\
5.8(-2.4 \text { to } 16.2) \\
7.2(-1.8 \text { to } 17.6)\end{array}$ & $\begin{array}{l}8.7(1.2 \text { to } 16.7) \\
8.8(0.9 \text { to } 16.7) \\
10.5(-0.1 \text { to } 19.6) \\
10.3(0.1 \text { to } 19.2) \\
11.5(2.8 \text { to } 20.4) \\
12.5(4.0 \text { to } 21.6)\end{array}$ & $\begin{array}{l}90.0 \\
79.2 \\
\\
53.0 \\
58.8 \\
\\
77.2 \\
88.9\end{array}$ \\
\hline
\end{tabular}




\begin{tabular}{|c|c|c|}
\hline \multicolumn{3}{|c|}{ CHU and precipitation (mm) accumulated during growing season ${ }^{\mathrm{c}}$} \\
\hline CHU & Precipitation \\
\hline St. Pauls 2015 & 3357 & 500.6 \\
Woodstock 2015 & 3471 & 460.4 \\
& & 400.0 \\
St. Pauls 2016 & 3423 & 448.8 \\
Woodstock 2016 & 3421 & 471.8 \\
St. Pauls 2017 & 3199 & 442.9 \\
Woodstock 2017 & 3408 & \\
\hline
\end{tabular}

${ }^{a}$ Environment and Climate Change Canada historical data was used for Woodstock temperatures. All temperature information was based on incomplete data. St. Pauls' temperature data was obtained from Weather Innovations Consulting LP

(https://www.weatherinnovations.com).

${ }^{b}$ Farmzone (2018) historical data for Woodstock - Oxford, Ontario, was used for Woodstock precipitation values. All Farmzone values are based on incomplete data sets.

'Farmzone (2018) historical data for Woodstock - Oxford, Ontario, was used for Woodstock CHU values. All Farmzone values are based on incomplete data sets. 
Table 4.2. Sucrose concentration for the University of Guelph panel in individual environments, combined years, combined locations and all environments. The lines were grown St. Pauls and Woodstock from 2015 to 2017.

\begin{tabular}{|c|c|c|c|}
\hline \multirow{4}{*}{$\begin{array}{l}\text { Individual } \\
\text { Environment }\end{array}$} & \multicolumn{3}{|c|}{ Sucrose concentration (\% seed composition) } \\
\hline & \multirow[t]{2}{*}{ Minimum } & \multirow[t]{2}{*}{ Maximum } & \multirow[t]{2}{*}{ Mean $(\mathrm{se})^{\mathrm{a}}$} \\
\hline & & & \\
\hline & \multicolumn{3}{|c|}{ Environment } \\
\hline St. Pauls 2015 & 5.17 & 8.87 & $7.38(0.066)$ \\
\hline Woodstock 2015 & 4.89 & 8.58 & $6.76(0.062)$ \\
\hline St. Pauls 2016 & 4.99 & 8.68 & $6.95(0.052)$ \\
\hline Woodstock 2016 & 5.22 & 8.96 & $7.21(0.061)$ \\
\hline St. Pauls 2017 & 5.29 & 9.31 & $7.19(0.065)$ \\
\hline Woodstock 2017 & 4.06 & 8.82 & $6.17(0.066)$ \\
\hline \multicolumn{4}{|l|}{ Location } \\
\hline St. Pauls & 4.99 & 9.31 & $7.16(0.036)$ \\
\hline Woodstock & 4.06 & 8.96 & $6.71(0.042)$ \\
\hline \multicolumn{4}{|l|}{ Year } \\
\hline 2015 & 4.89 & 8.87 & $7.17(0.061)$ \\
\hline 2016 & 4.99 & 8.96 & $6.99(0.062)$ \\
\hline 2017 & 4.06 & 9.31 & $6.68(0.054)$ \\
\hline All Environments & 4.06 & 9.31 & $6.95(0.045)$ \\
\hline
\end{tabular}

${ }^{\mathrm{a}}$ Data represents the standard errors $(\alpha=0.05)$. 


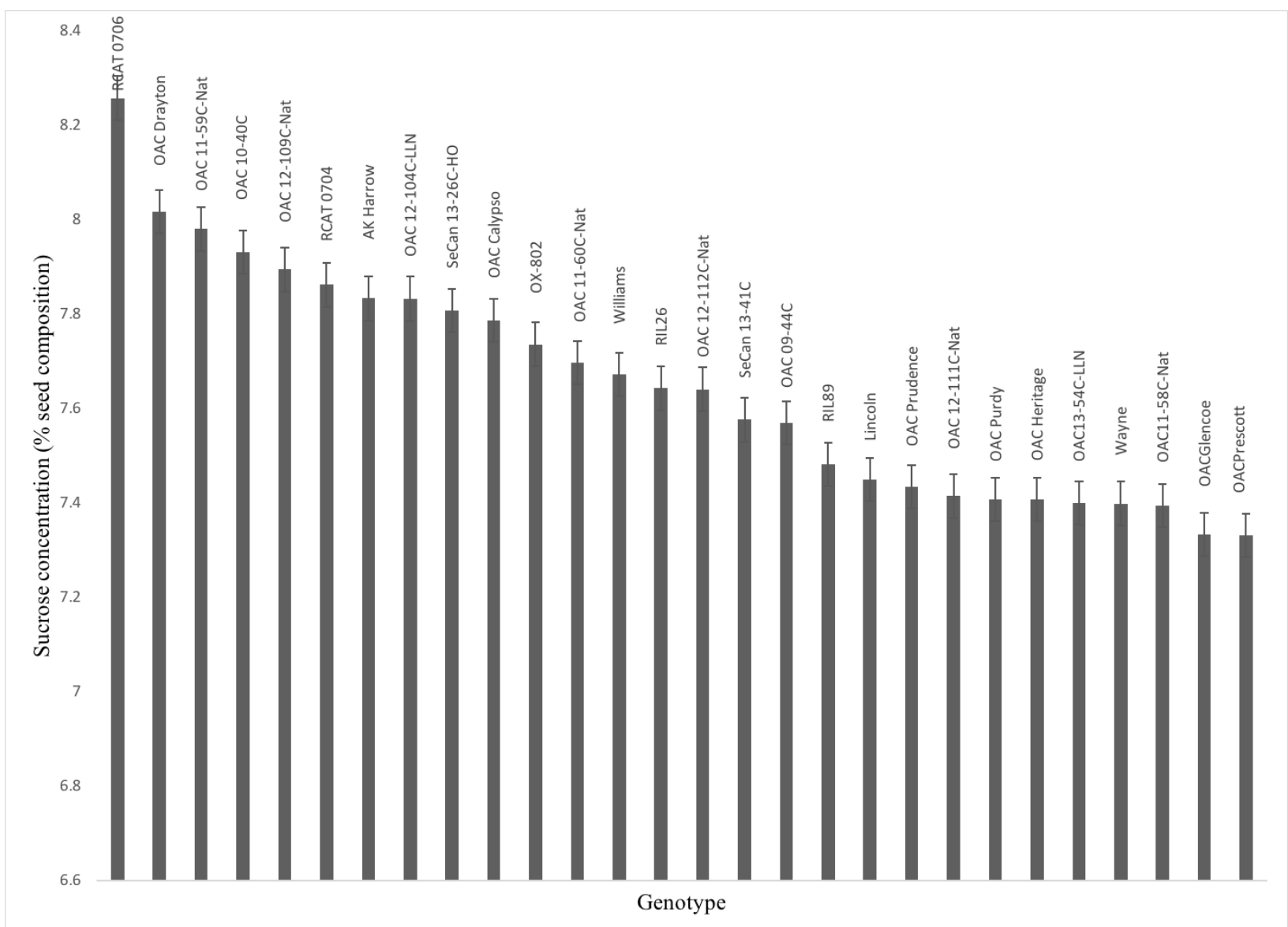

Figure 4.1. Top $20 \%$ of genotypes as a function of sucrose concentration (\%) combined over six environments. Error bars represent the standard error $(\alpha=0.05)$. 
Table 4.3. Combined environment analysis of variance of sucrose concentration (\%) of a trial consisting of 140 genotypes from the University of Guelph germplasm grown at two locations, St. Pauls and Woodstock, Ontario, from 2015 to 2017.

\begin{tabular}{lllll}
\hline Random effect & Estimate & Standard error ${ }^{\mathrm{a}}$ & Z value & $\operatorname{Pr}>\mathrm{Z}$ \\
\hline block(Environment) & 0.003 & 0.002 & 1.50 & 0.067 \\
Residual & 0.066 & 0.003 & 20.42 & $<.0001$ \\
& & & & \\
Fixed effects & Num df & Den df & F value & $\operatorname{Pr}>$ F \\
\hline Genotype & 139 & 834 & 49.32 & $<.0001$ \\
Environment & 5 & 6 & 110.31 & $<.0001$ \\
Genotype x Environment & 695 & 834 & 11.54 & $<.0001$ \\
\hline
\end{tabular}

${ }^{\mathrm{a}} \alpha=0.05$

Table 4.5. Summary of $F$ statistics and percentage of $G$ and GE variation explained by principal components generated by singular value decomposition (SVD) of environmentcentered values for seed sucrose concentration.

\begin{tabular}{lllllll}
\hline Trait & $\begin{array}{l}\text { Percent } \\
\text { of } \\
\text { Variation }\end{array}$ & $\begin{array}{l}\text { Cumulative } \\
\text { Percent of } \\
\text { Variation }\end{array}$ & MS & df & F Value & Pr $>$ F \\
\hline $\begin{array}{l}\text { Sucrose } \\
\text { concentration }\end{array}$ & & & & & & \\
\hline PC1 & 54.65 & 54.65 & 6.17 & 144 & 39.07 & $<.0001$ \\
PC2 & 14.30 & 68.95 & 1.64 & 142 & 10.37 & $<.0001$ \\
\hline
\end{tabular}




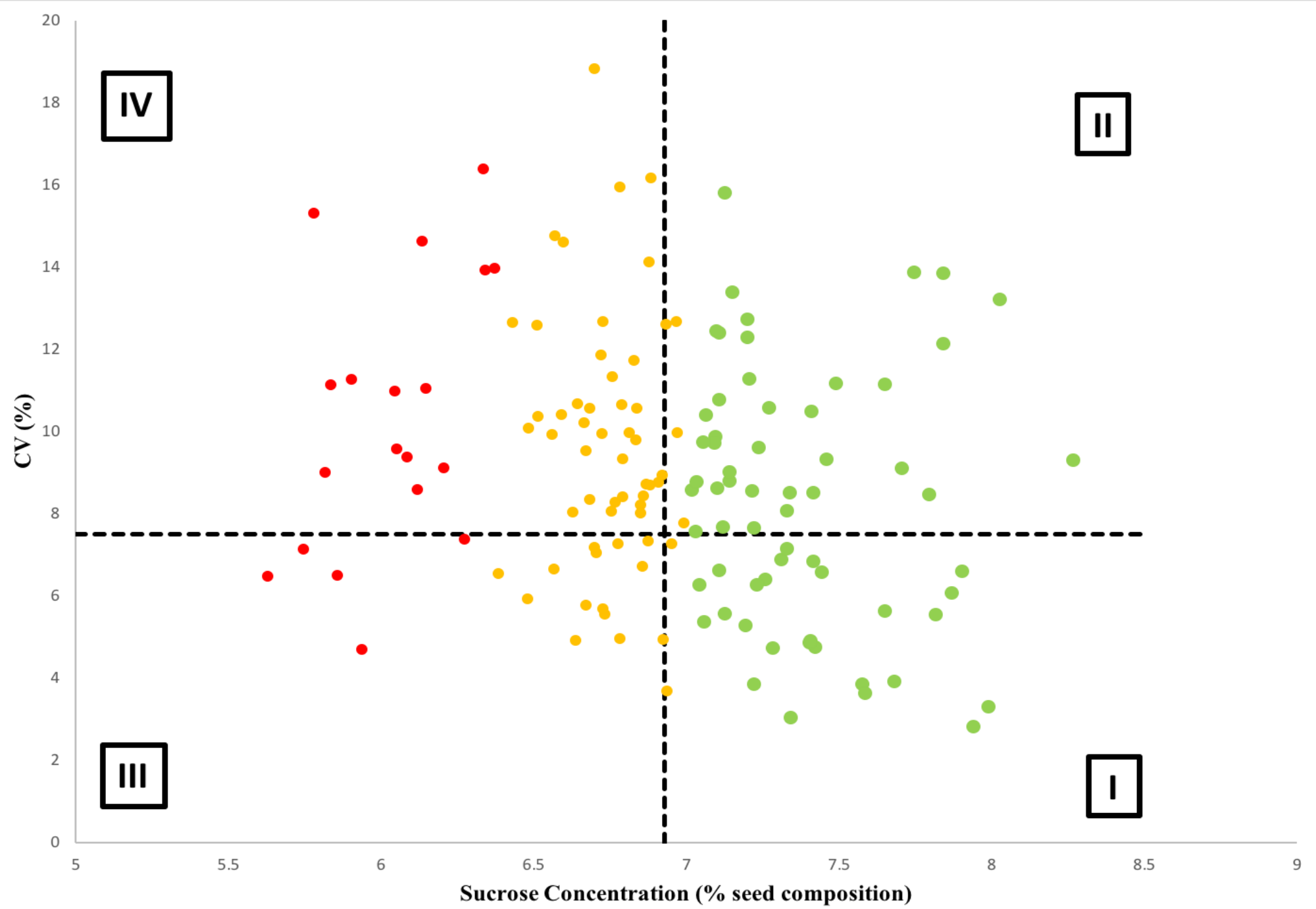

Figure 4.2. Plot of mean sucrose concentration performance against CV in a 140 genotype soybean diversity panel. The experiment was grown at St. Pauls and Woodstock, Ontario, from 2015 to 2017. High sucrose lines are represented by green dots, average sucrose lines are represented by orange dots and low sucrose lines are represented by red dots. 


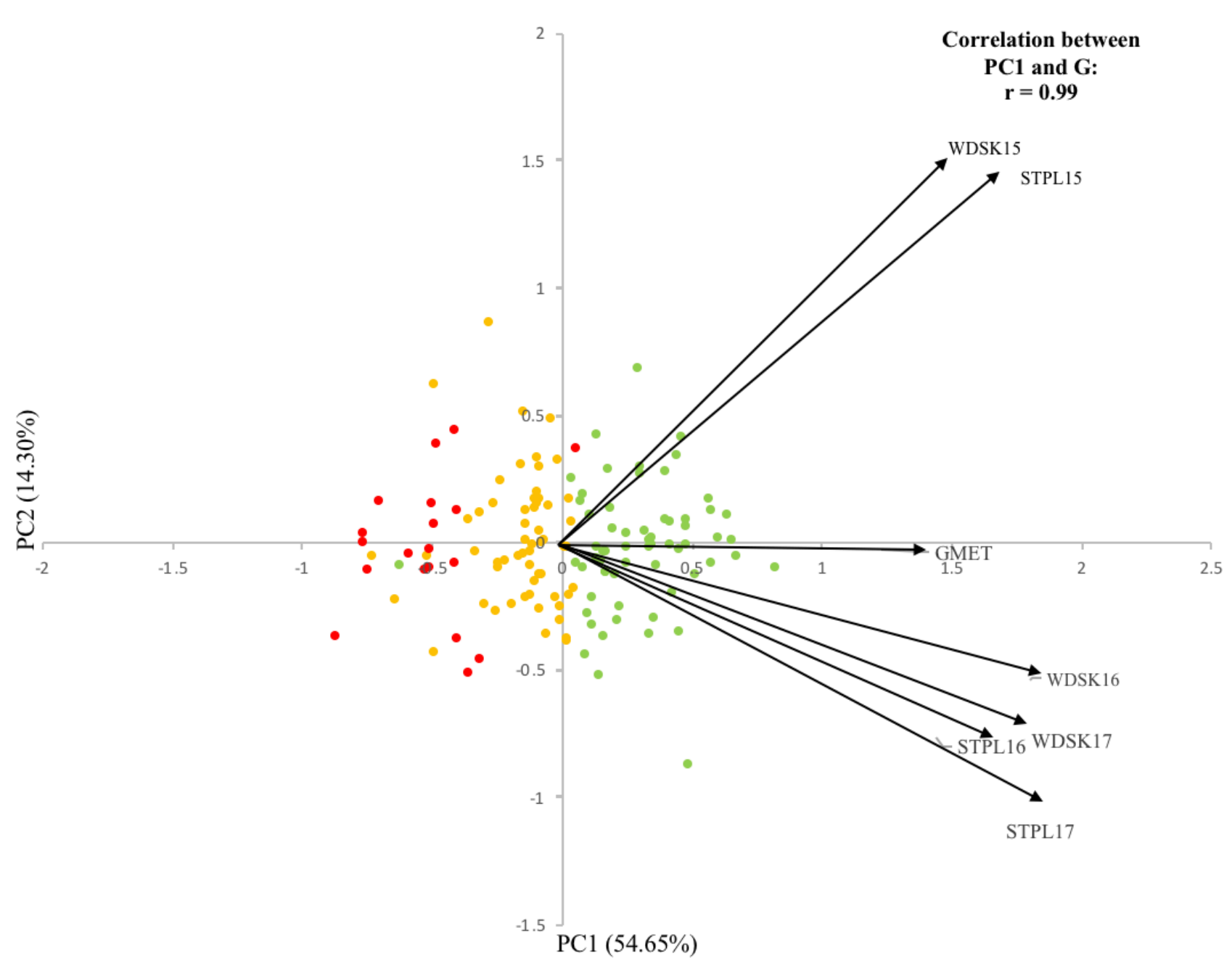

Figure 4.3. GGE biplot for sucrose concentration (\%) of the seed of a 140 line panel of genotypes grown at two locations, St. Pauls and Woodstock, Ontario, over three years, 2015 to 2017. High sucrose lines are represented by green dots, average sucrose lines are represented by orange dots and low sucrose lines are represented by red dots. 


\section{Chapter 5: General Discussion and Future Directions}

\subsection{General Discussion}

Soybean is a crop of economic importance, which is grown for its high protein and oil content in the seed. However, with the recent increase in interest of soy-derived food products, different seed traits are becoming important as well. One of these traits is sucrose concentration, which is of interest because of its direct effect on the taste of soy-derived food products (Hou et al. 2009).

The first hypothesis of this study was that sucrose concentration is a quantitative trait that is governed by quantitative trait loci (QTL). Two hundred and ninety-six genotypes were grown and analyzed for variability in sucrose concentration. Genotyping-by-sequencing was carried out to accompany phenotypic data from the field. Significant negative correlations between sucrose concentration and protein corroborated earlier findings (Hymowitz et al. 1972; Li et al. 2012). GAPIT was used for GWAS analysis (Lipka et al. 2012). A putative QTL was identified on chromosome 6, which was shown to be located near the soybean GAPC1 gene. Previous studies have noted that positive relationship between GAPC1 and oil seed accumulation, and the positive relationship between seed oil and seed sucrose accumulation (Hymowitz et al. 1972; Guo et al. 2014; Li et al. 2012). The findings of this study suggest that the GAPCl gene may play a role in soybean seed sucrose accumulation.

The second hypothesis of this study was that allelic diversity for sucrose concentration has decreased significantly after selection for other key soybean traits, including yield, protein and oil. Two hundred and eighty-two lines were used to determine haplotype groups within the diversity panel, dividing the panel into eight unique groups based on alleles present surrounding the GAPC1 gene. The findings of this study suggest that there has been a significant decrease in allelic 
variation present in the University of Guelph germplasm, and that introgression of genes that provide sucrose concentration variability would be warranted for further development of high sucrose soybean cultivars.

The third hypothesis of this study was that there are significant genotype, environment, and genotype-by-environment (GE) interaction effects on seed sucrose concentration. A diversity panel of 140 genotypes were grown in two Southern Ontario locations from 2015 to 2017, which demonstrated that all of the aforementioned interactions significantly affected seed sucrose concentration, and identified three stable, high-sucrose lines, RCAT 0706, OAC 10-40C (DS143C0) and OAC 11-59C-Tof. The findings of this study suggest that breeders may need to attempt to integrate exotic germplasm into their existing breeding programs in order to increase overall seed sucrose concentration variation to ensure the successful development of new and improved soybean cultivars.

In conclusion, the QTL identified in this study may have a minor role in overall seed sucrose concentration, however more studies should be carried out. Allele fixation has occurred for sucrose concentration, and has highly likely affected other seed traits that have not been heavily selected for. In order to increase the variation available to breeders, the introduction of exotic germplasm from seed banks is necessary. Finally, the identification of both well performing and poor performing genotypes for sucrose concentration suggests that it is possible to breed for higher sucrose cultivars in the future.

\subsection{Limitations}

As with any scientific research, there are potential sources of error. The diversity panel was comprised of 296 different genotypes; however, the majority of the lines were developed at the 
University of Guelph or the University of Guelph Ridgetown Campus. Therefore, there is a potential that a number of these lines are highly similar due to having the similar pedigrees recent or more distant history. As a result, some GWAS analytical power likely was lost for sucrose concentration assessment, which may also account for the ability to find only one putative QTL for sucrose concentration.

Furthermore, field notes and the transfer of data from the field to the database holds the potential of human error, which despite not being detected, should be considered.

\subsection{Future directions}

In order to determine the contribution of the putative QTL on chromosome 6 to overall seed sucrose accumulation, further studies should be carried out. In order to increase the statistical power necessary to detect more QTL, a diversity panel consisting of exotic germplasm as well as released cultivars from the University of Guelph should be used. Further studies regarding genecentered allelic fixation should also be carried out in order to assess the proper steps to increase the overall variation that is available to Canadian breeders. Studying and analyzing seed traits other than yield, oil and protein are necessary in order to develop new food-grade cultivars for the agrifood sector, and should implemented in breeding programs around the world. 


\section{Literature Cited}

Abdel-Shafy H, Bortfeldt RH, Tetens J, Brockmann GA. 2014. Single nucleotide polymorphism and haplotype effects associated with somatic cell score in German Holstein cattle. Genet Sel Evol., 46:35.

Bradbury PJ, Zhang Z, Casstevens TM, Ramdoss Y, Buckler ES. 2007. TASSEL: software for association mapping of complex traits in diverse samples. Bioinformatics, 23:2633-2635.

Brar GS, Carter TE. 1993. Soybean Glycine max (L.) Merrill. In G. Kalloo and B.O. Bergh (ed.) Genetic improvement of vegetable crops. Pergamon Press, New York. Pp. 427-463.

Browning SR, Browning BL. Rapid and accurate haplotype phasing and missing-data inference for whole-genome association studies by use of localized haplotype clustering. Am J Hum Genet., 81:1084-1097.

Carter JL, Hopper TH. 1942. Influence of variety, environment and fertility level on the chemical composition of soybean seed. USDA Tech. Bull. 787.

Carter TE Jr, Wilson RF. 1998. Soybean quality for human consumption. Soybean's role in Australia. In J. Andrew (ed.) Proc. Australian Soybean Conference, 10 $0^{\text {th }}$, Brisbane, Australia. CSIRO Tropical Agriculture, St. Lucia, Australia. 1-16.

Chan EY. 2005. Advances in sequencing technology. Mutat Res., 573:13-40.

Choung M. 2010. Determination of sucrose content in soybean using near-infrared reflectance spectroscopy. J Korean Soc Appl Biol Chem., 53:478-484.

Contreras-Soto RI, Mora F, Rott de Oliveira MA, Higashi W, Scapim CA, Schuster I. 2017. A genome-wide association study for agronomic traits in soybean using SNP markers and SNP-based haplotype analysis. PLOS ONE, 12:e0171105. 
Cornelius PL, Crossa J, Seyedsadr MS. 1996. Statistical tests and estimators of multiplicative models for genotype-by-environment interaction, in: Kang, M.S.; Gauch, H.G. (Eds.), Genotype-by-Environment Interaction. CRC Press, Boca Raton, FL, USA, pp. 199-234.

Elshire RJ, Glaubitz JC, Sun Q, Poland JA, Kawamoto K, Buckler ES, Mitchell SE. 2011. A robust, simple genotyping-by-sequencing (GBS) approach for high diversity species. PLoS ONE, 6:e19379.

Fang C, Ma Y, Wu S, Zhi L, Zheng W, Yang R, Hu G, Zhou Z, Yu H, Zhang M, Pan Y, Zhou G, Ren G, Du W, Yan H, Wang Y, Han D, Shen Y, Liu S, Liu T, Zhang J, Qin H, Yuan J, Yuan X, Kong F, Liu B, Li J, Zhang Z, Wang G, Zhu B, Tian Z. 2017. Genome-wide association studies dissect the genetic networks underlying agronomical traits in soybean. Genome Biol., 18:161.

FAOSTAT. 2014. FAOSTAT Crop Production.

Farmzone. 2018. Historical Data. Available online: www.farmzone.com [Accessed 2018 March $10]$.

Fehr WR, Caviness CE, Burmood DT, Pennington JS. 1971. Stage of development descriptions for soybeans, Glycine max (L.) Merrill. Crop Sci., 11:929.931.

Francis TR, Kannenberg LW. 1978. Yield stability studies in short season maize. I: A descriptive method for grouping genotypes. Can J Plant Sci., 58:1029-1034.

Fukuda Y. 1933. Cytogenetical studies on the wild and cultivated Manchurian soybeans. Jap J Bot., 6:489-506.

Giannoccaro E, Wang YJ, Chen P. 2008. Comparison of two HPLC systems and an enzymatic method for quantification of soybean sugars. Food Chem., 106:324-330. 
Gnome Project. 2017. The gnumeric spreadsheet: free, fast, accurate --- pick any three. Accessed 2017 September 2].

Guo C, Oosterhuis DM. 1995. Pinitol occurrence in soybean plants as affected by temperature and plant growth regulators. $J$ Exp Bot., 46:249-253.

Guo L, Devaiah SP, Narasimhan R, Pan X, Zhang Y, Zhang W, Wang X. 2012. Cytosolic glyceraldehyde-3-phosphate dehydrogenases interact with phospholipase $\mathrm{D} \delta$ to transduce hydrogen peroxide signals in the Arabidopsis response to stress. Plant Cell., 24:2200-2212.

Guo L, Ma F, Wei F, Fanella B, Allen DK, Wang X. 2014. Cytosolic phosphorylating glyceraldehyde-3-phosphate dehydrogenases affect Arabidopsis cellulr metabolism and promote seed oil accumulation. Plant Cell., 26:3023-3035.

Gur A, Zamir D. 2004. Unused natural variation can lift yield barriers in plant breeding. PLoS ONE, 2:e245.

Guy CL, Huber JLA, Huber SC. 1992. Sucrose phosphate synthase and sucrose accumulation at low temperature. Plant Physiol., 100:502-508.

Hancock JT, Henson D, Nyirenda M, Desikan R, Harrison J, Lewis M, Hughes J, Neill SJ. 2005. Proteomic identification of glyceraldehyde 3-phosphate dehydrogenase as an inhibitory target of hydrogen peroxide in Arabidopsis. Plant Physiol Biochem., 43:828-835.

Hartman GL, West ED, Herman TK. 2011. Crops that feed the world 2. Soybean-worldwide production, use, and constraints caused by pathogens and pests. Food Security, 3:5-17.

Heffner EL, Sorrells ME, Jannink JL. 2009. Genomic selection for crop improvement. Crop Sci., 49:1-12. 
Holtgrefe S, Gohlke J, Starmann J, Druce S, Klocke S, Altmann B, Wojtera J, Lindermayr C, Scheibe R. 2008. Regulation of plant cytosolic glyceraldehyde 3-phosphate dehydrogenase isoforms by thiol modifications. Physiol Plant., 133:211-228.

Hou A, Chen P, Alloatti J, Li D, Mozzoni L, Zhang B, Shi A. 2009. Genetic variability of seed sugar content in worldwide soybean germplasm collections. Crop Sci., 49:903-912.

Hou A, Chen P, Shi A, Zhang B, Wang YJ. 2009. Sugar variation in soybean seed assessed with a rapid extraction and quantification method. Intl J Agr., Article ID 484571.

Huang X, Wei X, Sang T, Zhao Q, Feng Q, Zhao Y, Li C, Zhu C, Lu T, Zhang Z, Li M, Fan D, Guo Y, Wang A, Deng L, Li W, Lu Y, Weng Q, Liu K, Huang T, Zhou T, Jing Y, Li W, Lin Z, Buckler ES, Qian Q, Zhang QF, Li J, Han B. 2010. Genome-wide association studies of 14 agronomic traits in rice landraces. Nat Genet., 42:961-967.

Huang X, Zhao Y, Wei X, Li C, Wang A, Zhao Q, Li W, Guo Y, Deng L, Zhu C, Fan D, Lu Y, Weng Q, Liu K, Zhou T, Jing Y, Si L, Dong G, Huang T, Lu T, Feg Q, Qian Q, Li J, Han B. 2011. Genome-wide association study of flowering time and grain yield traits in a worldwide collection of rice germplasm. Nat Genet., 4:32-39.

Hwang EY, Song Q, Jia G, Specht JE, Hyten DL, Costa J, Cregan PB. 2014. A genome-wide association study of seed protein and oil content in soybean. BMC Genomics, 15:1-12.

Hymowitz T. 1970. On the domestication of the soybean. Econ Bot. 24:408-421.

Hymowitz T, Collins FI, Panczner J, Walker WM. 1972. Relationship between the content of oil, protein, and sugar in soybean seed. Agron J., 64:613-616.

Hymowitz T, Collins FI. 1974. Variability of sugar content in seed of Glycine max (L.) Merril and G. soja Sieb. and Zucc. Agron J., 66:129-240. 
Hymowitz T, Newell CA. 1981. Taxonomy of the genus Glycine, domestication and uses of soybeans. Econ Bot., 35:272-288.

Kang HM, Zaitlen NA, Wade CM, Kirby A, Heckerman D, Daly MJ, Eskin E. 2008. Efficient control of population structure in model organism association mapping. Genetics, 178:1709-1723.

Kim HK, Kang ST, Cho JH, Choung MG, Suhd Y. 2005. Quantitative trait loci associated with oligosaccharide and sucrose contents in soybean (Glycine max L.). J. Plant Biol., 48:106112.

Kim SL, Berhow MA, Kim JT, Chi HY, Lee SJ, Chung IM. 2006. Evaluation of soyasaponin, isoflavone, protein, lipid, and free sugar accumulation in developing soybean seeds. $J$ Agric Food Chem., 54:10003-10010.

Korte A, Farlow A. 2013. The advantages and limitations of trait analysis with GWAS: a review. Plant Methods, 9:29.

Kumar GR, Sakthivel K, Sundaram RM, Neeraja CN, Balachandran SM, Shobha Rani N, Viraktamath BC, Madhav MS. 2010. Allele mining in crops: prospects and potentials. Biotechnol Adv., 28:451-461.

Kumar V, Rani A, Goyal L, Kumar Dixit A, Manjaya JG, Dev J, Swamy M. 2010. Sucrose and raffinose family oligosaccharides (RFOs) in soybean seeds as influenced by genotype and growing location. J Agric Food Chem., 58:5081-5085.

Ladizinsky G. 1998. Plant evolution under domestication. Kluwer Academic Press, Dordrecht, HL.

Latha R, Rubia L, Bennett J, Swaminathan MS. Allele mining for stress tolerance genes in Oryza species and related germplasm. Mol Biotechnol., 27:101-108. 
Li H, Peng Z, Yang Z, Wang W, Fu J, Wang J, Han Y, Chai Y, Guo T, Yang N, Liu J, Warburton ML, Cheng Y, Hao X, Zhang P, Zhao J, Liu Y, Wang G, Li J, Yan J. 2013. Genome-wide association study dissects the genetic architecture of oil biosynthesis in maize kernels. Nat Genet., 45:43-50.

Li M, Liu X, Bradbury PJ, Yu J, Zhang YM, Todhunter RJ, Buckler ES, Zhang Z. 2014. Enrichment of statistical power for genome-wide association studies. BMC Biol., 12:73.

Lipka AE, Tian F, Wang Q, Peiffer J, Li M, Bradbury PJ, Gore MA, Buckler ES, Zhang Z. 2012. GAPIT: genome association and prediction integrated tool. Bioinformatics, 15:2397-2399.

Mardis ER. 2008. Next-generation DNA sequencing methods. Trends Genet., 9:387-402.

Mascher M, Jost M, Kuon JE, Himmelback A, A $\beta$ flag A, Beier S, Scholz U, Graner A, Stein N. 2014. Mapping-by-sequencing accelerates forward genetics in barley. Genome Biol., 15:R78.

Maughan PJ, Maroof MAS, Buss GR. 2000. Identification of quantitative trait loci controlling sucrose content in soybean (Glycine max). Mol Breed., 6:105-111.

Messina M, Messina V. 1991. Increasing use of soyfoods and their potential in cancer prevention. J Am Diet Assoc., 91:836-840.

Openshaw SJ, Hadley HH. 1981. Selection to modify sugar content of soybean seeds. Crop Sci., 21:9-12.

Palmer RG, Hymowitz T, Nelson RL. 1996. In D.P.S. Verma and R.C. Shoemaker (ed.) Soybean: Genetics, molecular biology, and biotechnology. CAB Int., Wallingford, UK. 
Pazur JH, Shadaksharaswamy M, Meidell GE. 1962. The metabolism of oligosaccharides in germinating soybeans, Glycine max. Arch Biochem Biophys., 99:78-85.

Poland JA, Bradbury PJ, Buckler ES, Nelson RJ. 2011. Genome-wide nested association mapping of quantitative resistance to northern leaf blight in maize. Proc Natl Acad Sci., 108:68936898.

Qiu LJ, Zing LL, Guo Y, Wang J, Jackson SA, Chang RZ. 2013. A platform for soybean molecular breeding: the utilization of core collections for food security. Plant Mol Bio., 83:41-50.

Rao MSS, Mullinix BG, Rangappa M, Cebert E, Bhagsari AS, Sapra VT, Joshi JM, Dadson RB. 2002. Genotype x environment interactions and yield stability of food-grade soybean genotypes. Agron J., 94:72-80.

Saghai Maroof MA, Buss GR. 2008. Low phytic acid, low stachyose, high sucrose soybean lines. U.S. Patent Application 0199591 A1. Date issued: pending.

SAS Institute 2013. SAS ${ }^{9}$ 9.4. SAS Institute. Cary, NC.

Sato T, Zahlner V, Berghofer E, Lošák T, Vollmann J. 2012. Near-infrared reflectance calibrations for determining sucrose content in soybean breeding using artificial reference samples. Plant Breeding, 131:531-534.

Segura V, Vilhjálmsson BJ, Platt A, Korte A, Seren Ü, Long Q, Nordborg M. 2012. An efficient multi-locus mixed-model approach for genome-wide association studies in structured populations. Nat Genet., 44:825-830.

Shapiro SS, Wilk MB. 1965. An analysis of variance test for normality (complete series). Biometrika, 52(3/4):591-611. 
Shi A, Chen P, Zhang B, Hou A. 2010. Genetic diversity and association analysis of protein and oil content in food-grade soybeans from Asia and the United States. Plant Breeding, 129:250-256.

Skoneczka JA, Saghai Maroof MA, Shang C, Buss GR. 2009. Identification of candidate gene mutation associated with low stachyose phenotype in soybean line PI200508. Crop Sci., 49:247-255.

Sonah H, Bastien M, Iquira E, Tardivel A, Legare G, Boyle B, Normandeau E, Laroche J, Larose S, Jean M, Belzile F. 2013. An improved genotyping by sequencing (GBS) approach offering increased versatility and efficiency of SNP discovery and genotyping. PLOS ONE, 8:e54603.

Sonah H, O'Donoughue L, Cober E, Rajcan I, Belzile F. 2015. Identification of loci governing eight agronomic traits using a GBS-GWAS approach and validation by QTL mapping in soya bean. Plant Biotech J., 13:211-221.

Sugano M. 2006. 1. Nutritional implications of soy, in M. Sugano, ed. Soy in Health and Disease Prevention. CRC Press, Taylor and Francis group, New York, pp. $1-16$.

Taira H. 1990. Quality of soybean for processed foods in Japan. Jpn Agric Res Q. 24:224-230.

Tanksley SD, McCouch SR. 1997. Seed banks and molecular maps: unlocking genetic potential from the wild. Science, 277:1063-1066.

Tester M, Langridge P. 2010. Breeding technologies to increase crop production in a changing world. Science, 327:818-822.

Teixeira AI, Ribeiro LF, Rezende ST, Barros EG, Moreira MA. 2012. Development of a method to quantify sucrose in soybean grains. Food Chem., 130: 1134-1136. 
Tian F, Bradbury PJ, Brown PJ, Hung H, Sun Q, Flint-Garcia S, Rocheford TR, McMullen MD, Holland JB, Buckler ES. 2011. Genome-wide association study of leaf architecture in the maize nested association mapping population. Nat Genet., 43:159-162.

Torkamaneh D, Belzile F. 2015. Scanning and filling: ultra-dense SNP genotyping combining genotyping-by-sequencing, SNP array and whole-genome resequencing data. PLOS ONE, 10:e0131533.

Torkamaneh D, Laroche J, Tardivel A, O’Donoughue L, Cober E, Rajcan I, Belzile F. 2017. Comprehensive description of genomewide nucleotide and structural variation in shortseason soya bean. Plant Biotechnol J., 16:749:759.

Torkamaneh D, Boyle B, Belzile F. 2018. Efficient genome-wide genotyping strategies and data integration in crop plants. Theor Appl Genet., 131:499-511.

USDA-ARS National Genetic Resources Program. 2003. Germplasm Resources Information Network (GRIN) [Online Database]. National Germplasm Resources Laboratory, Beltsville, MD.

Vavilov NI. 1951. The origin, variation, immunity, and breeding of cultivated plants. Chronica botanica. Vol. 13. Ronald Press, New York.

Wang M, Yan J, Zhao J, Song W, Zhang X, Xiao Y, Zheng Y. 2012. Genome-wide association study (GWAS) of resistance to head smut in maize. Plant Sci., 196:125-131.

Wang Q, Tian F, Pan Y, Buckler ES, Zhang Z. 2014. A SUPER powerful method for genome wide association study. PLoS ONE, 9:e107684.

Wang Y, Chen P, Zhang B. 2014. Quantitative trait loci analysis of soluble sugar contents in soybean. Plant Breeding, 133:493-498. 
Wolf RB, Cavins JF, Kleiman R, Black LT. 1982. Effect of temperature on soybean seed constituents: oil, protein, moisture, fatty acids, amino acids and sugars. $\mathrm{J}$ Am Oil Chem Soc., 59:230-232.

Yan W, Hunt LA, Sheng Q, Szlavnics Z. 2000. Cultivar evaluation and mega-environment investigation based on the GGE biplot. Crop Sci., 40:597.

Yan W, Rajcan I. 2002. Biplot analysis of test sites and trait relations of soybean in Ontario. Crop Sci., 42:11-20.

Yan W, Kang MS, Ma B, Woods S, Cornelius PL. 2007. GGE biplot vs. AMMI analysis of genotype-by-environment data. Crop Sci., 47:643-653.

Young VR. 1991. Soy protein in relation to human protein and amino acid nutrition. J Am Diet Assoc., 91:828-835.

Yu J, Pressoir G, Briggs WH, Vroh BI, Yamasaki M, Doebley JF, McMullen MD, Gaut BS, Nielsen DM, Holland JB, Kresovich S, Buckler ES. 2006. A unified mixed-model method for association mapping that accounts for multiple levels of relatedness. Nat Genet., 38:203-208.

Zeng A, Chen P, Shi A, Wang D, Zhang B, Orazaly M, Florez-Palacios L, Brye K, Song Q, Cregan P. 2015. Identification of quantitative trait loci for sucrose content in soybean seed. Crop Sci., 54:554-564.

Zhang J, Song Q, Cregan PB, Nelson RL, Wang X, Wu J, Jiang GL. 2015. Genome-wide association study for flowering time, maturity dates and plant height in early maturing soybean (Glycine max) germplasm. BMC Genomics, 16:217. 
Appendix I. Soybean genotype mean sucrose concentration ( \pm standard error) over six environments. Data represent the LSMEANS.

\begin{tabular}{|c|c|c|c|}
\hline Entry no. & Genotype & $\begin{array}{l}\text { Sucrose concentration } \\
\pm \text { standard error }{ }^{\mathrm{a}}(\%)\end{array}$ & Letter group ${ }^{b}$ \\
\hline 1 & 05SI03-02 & $7.21 \pm 0.31$ & ABCDEFGH \\
\hline 2 & 10S63C-05 & $7.12 \pm 0.31$ & $\mathrm{ABCDEF}$ \\
\hline 3 & 10S90C-33 & $7.83 \pm 0.31$ & $\mathrm{ABCD}$ \\
\hline 4 & 12S06C-03 & $7.89 \pm 0.31$ & ABCDEFG \\
\hline 5 & 12S06C-09 & $7.41 \pm 0.31$ & FGH \\
\hline 6 & 12S06C-18 & $7.64 \pm 0.31$ & EFGH \\
\hline 7 & $12 \mathrm{~S} 06 \mathrm{C}-23$ & $6.03 \pm 0.31$ & BCDEFGH \\
\hline 8 & $12 \mathrm{~S} 06 \mathrm{C}-25$ & $6.55 \pm 0.31$ & $\mathrm{H}$ \\
\hline 9 & Acme & $5.85 \pm 0.31$ & ABCDEFG \\
\hline 10 & AK Harrow & $6.04 \pm 0.31$ & ABCDEFGH \\
\hline 11 & Altona & $5.81 \pm 0.31$ & ABCDEFGH \\
\hline 12 & Bicentennial & $5.83 \pm 0.31$ & BCDEFGH \\
\hline 13 & Blackhawk & $7.19 \pm 0.31$ & ABCDEFGH \\
\hline 14 & Capital & $7.83 \pm 0.31$ & ABCDEFGH \\
\hline 15 & Chikala & $6.63 \pm 0.31$ & ABCDEFGH \\
\hline 16 & Chippewa & $6.27 \pm 0.31$ & ABCDEFG \\
\hline 17 & Colby & $6.68 \pm 0.31$ & ABCDEF \\
\hline 18 & DH420 & $6.66 \pm 0.31$ & ABCDEFGH \\
\hline 19 & DH530 & $6.86 \pm 0.31$ & ABCDEFG \\
\hline 20 & DH618 & $7.30 \pm 0.31$ & FGH \\
\hline 21 & DH748 & $7.10 \pm 0.31$ & ABCDEFG \\
\hline 22 & Evans & $7.14 \pm 0.31$ & ABCDEFGH \\
\hline 23 & Factor & $7.14 \pm 0.31$ & ABCDEFGH \\
\hline 24 & Hark & $6.38 \pm 0.31$ & $\mathrm{ABCD}$ \\
\hline 25 & Harosoy & $6.80 \pm 0.31$ & ABCDEFGH \\
\hline 26 & Harosoy 63 & $6.82 \pm 0.31$ & ABCDEFGH \\
\hline 27 & Harovinton & $7.03 \pm 0.31$ & ABCDEFGH \\
\hline 28 & Hawkeye & $6.24 \pm 0.31$ & BCDEFGH \\
\hline 29 & Heinong 38 & $6.72 \pm 0.31$ & ABCDEFGH \\
\hline 30 & HS 13C 38 & $6.88 \pm 0.31$ & ABCDEFGH \\
\hline 31 & Leo & $6.52 \pm 0.31$ & ABCDEFGH \\
\hline 32 & Lincoln & $7.32 \pm 0.31$ & ABCDEFGH \\
\hline 33 & Manchu & $6.68 \pm 0.31$ & ABCDEFGH \\
\hline 34 & Mandarin & $6.67 \pm 0.31$ & ABCDEFGH \\
\hline 35 & Maple Arrow & $6.83 \pm 0.31$ & ABCDEFGH \\
\hline 36 & McCall & $7.60 \pm 0.31$ & ABCDEFG \\
\hline
\end{tabular}




\begin{tabular}{|c|c|c|c|}
\hline 37 & Merit & $7.20 \pm 0.31$ & ABCDEFGH \\
\hline 38 & Mukden & $6.26 \pm 0.31$ & BCDEFGH \\
\hline 39 & OAC 05-02 & $6.06 \pm 0.31$ & DEFGH \\
\hline 40 & OAC 06-03 & $6.08 \pm 0.31$ & BCDEFGH \\
\hline 41 & OAC 07-03 & $6.22 \pm 0.31$ & BCDEFGH \\
\hline 42 & OAC 07-26 & $6.19 \pm 0.31$ & BCDEFGH \\
\hline 43 & OAC 07-31 & $6.79 \pm 0.31$ & ABCDEFGH \\
\hline 44 & OAC 09-35 & $7.29 \pm 0.31$ & ABCDEFGH \\
\hline 45 & OAC 09-44 & $7.63 \pm 0.31$ & ABCDEFG \\
\hline 46 & OAC $10-40$ & $6.96 \pm 0.31$ & ABCDEFGH \\
\hline 47 & OAC 11-56C-Tof & $6.19 \pm 0.31$ & BCDEFGH \\
\hline 48 & OAC 11-58C-Nat & $7.78 \pm 0.31$ & $\mathrm{ABCDEF}$ \\
\hline 49 & OAC 11-59C-Nat & $7.99 \pm 0.31$ & $\mathrm{ABC}$ \\
\hline 50 & OAC 12-104C-LLN & $6.09 \pm 0.31$ & ABCDEFGH \\
\hline 51 & OAC $12-107 \mathrm{C}-\mathrm{HO}$ & $7.99 \pm 0.31$ & $\mathrm{AB}$ \\
\hline 52 & OAC 12-109C-Nat & $7.09 \pm 0.31$ & ABCDEFG \\
\hline 53 & OAC 12-111C-Nat & $7.57 \pm 0.31$ & $\mathrm{ABCDEF}$ \\
\hline 54 & OAC 12-112C-Nat & $7.93 \pm 0.31$ & $\mathrm{AB}$ \\
\hline 55 & OAC $13-25 \mathrm{C}-\mathrm{HO}$ & $7.48 \pm 0.31$ & ABCDEFG \\
\hline 56 & OAC $13-27 \mathrm{C}-\mathrm{HO}$ & $7.50 \pm 0.31$ & ABCDEFG \\
\hline 57 & OAC 13-29C-HO & $7.70 \pm 0.31$ & $\mathrm{ABCDEF}$ \\
\hline 58 & OAC 13-48C-T & $7.11 \pm 0.31$ & ABCDEFGH \\
\hline 59 & OAC 13-49C-T & $7.06 \pm 0.31$ & ABCDEFGH \\
\hline 60 & OAC 13-50C-ZL & $6.04 \pm 0.31$ & DEFGH \\
\hline 61 & OAC 13-51C-ZL & $6.57 \pm 0.31$ & ABCDEFGH \\
\hline 62 & OAC 13-52C-ZL & $6.98 \pm 0.31$ & ABCDEFGH \\
\hline 63 & OAC 13-53C-LLN & $6.73 \pm 0.31$ & ABCDEFGH \\
\hline 64 & OAC 13-54C-LLN & $7.44 \pm 0.31$ & ABCDEFGH \\
\hline 65 & OAC 13-55C-HL & $7.32 \pm 0.31$ & ABCDEFGH \\
\hline 66 & OAC 13-59C-ChCdn & $6.96 \pm 0.31$ & ABCDEFGH \\
\hline 67 & OAC 13-60C-ChCdn & $6.06 \pm 0.31$ & CDEFGH \\
\hline 68 & OAC 13-61C-ChCdn & $6.44 \pm 0.31$ & ABCDEFGH \\
\hline 69 & OAC 13-66C-ChCdn & $6.84 \pm 0.31$ & ABCDEFGH \\
\hline 70 & OAC 13-67C-ChCdn & $6.96 \pm 0.31$ & ABCDEFGH \\
\hline 71 & OAC 13-71C-ChCdn & $6.88 \pm 0.31$ & ABCDEFGH \\
\hline 72 & OAC 13-86C-ChCdn & $7.22 \pm 0.31$ & ABCDEFGH \\
\hline 73 & OAC 13-87C-ChCdn & $7.02 \pm 0.31$ & ABCDEFGH \\
\hline 74 & OAC Bayfield & $7.03 \pm 0.31$ & ABCDEFGH \\
\hline 75 & OAC Belgrave & $6.79 \pm 0.31$ & ABCDEFGH \\
\hline 76 & OAC Blythe & $7.67 \pm 0.31$ & ABCDEF \\
\hline
\end{tabular}




\begin{tabular}{|c|c|c|c|}
\hline 77 & OAC Calypso & $7.68 \pm 0.31$ & ABCDEFG \\
\hline 78 & OAC Carman & $6.38 \pm 0.31$ & ABCDEFGH \\
\hline 79 & OAC Champion & $7.14 \pm 0.31$ & ABCDEFGH \\
\hline 80 & OAC Clinton & $7.25 \pm 0.31$ & ABCDEFGH \\
\hline 81 & OAC Drayton & $7.43 \pm 0.31$ & ABCDEFGH \\
\hline 82 & OAC Eramosa & $6.73 \pm 0.31$ & ABCDEFGH \\
\hline 83 & OAC Eve & $7.11 \pm 0.31$ & ABCDEFGH \\
\hline 84 & OAC Ginty & $6.73 \pm 0.31$ & ABCDEFGH \\
\hline 85 & OAC Glencoe & $7.59 \pm 0.31$ & ABCDEFG \\
\hline 86 & OAC Gretna & $6.52 \pm 0.31$ & ABCDEFGH \\
\hline 87 & OAC Huron & $7.13 \pm 0.31$ & ABCDEFGH \\
\hline 88 & OAC Kent & $7.13 \pm 0.31$ & ABCDEFGH \\
\hline 89 & OAC Lakeview & $7.52 \pm 0.31$ & ABCDEFG \\
\hline 90 & OAC Lauralain & $6.70 \pm 0.31$ & ABCDEFGH \\
\hline 91 & OAC Lindsy & $6.48 \pm 0.31$ & ABCDEFGH \\
\hline 92 & OAC Lucan & $6.35 \pm 0.31$ & ABCDEFGH \\
\hline 93 & OAC Madoc & $6.80 \pm 0.31$ & ABCDEFGH \\
\hline 94 & OAC Millenium & $6.72 \pm 0.31$ & ABCDEFGH \\
\hline 95 & OAC Morden & $6.82 \pm 0.31$ & ABCDEFGH \\
\hline 96 & OAC Prescott & $6.91 \pm 0.31$ & ABCDEFGH \\
\hline 97 & OAC Prodigy & $7.06 \pm 0.31$ & ABCDEFGH \\
\hline 98 & OAC Prudence & $6.96 \pm 0.31$ & ABCDEFGH \\
\hline 99 & OAC Purdy & $7.06 \pm 0.31$ & ABCDEFGH \\
\hline 100 & OAC Shire & $6.88 \pm 0.31$ & ABCDEFGH \\
\hline 101 & OAC Strive & $6.26 \pm 0.31$ & BCDEFGH \\
\hline 102 & OAC Sunny & $6.89 \pm 0.31$ & ABCDEFGH \\
\hline 103 & OAC Vision & $6.79 \pm 0.31$ & ABCDEFGH \\
\hline 104 & OAC Wallace & $7.07 \pm 0.31$ & ABCDEFGH \\
\hline 105 & OAC Wellington & $5.76 \pm 0.31$ & $\mathrm{GH}$ \\
\hline 106 & OAC Woodstock & $6.72 \pm 0.31$ & ABCDEFGH \\
\hline 107 & Ohgata & $6.24 \pm 0.31$ & BCDEFGH \\
\hline 108 & OT05-18 & $7.25 \pm 0.31$ & ABCDEFGH \\
\hline 109 & OX-802 & $7.17 \pm 0.31$ & ABCDEFGH \\
\hline 110 & Ozzie & $6.72 \pm 0.31$ & ABCDEFGH \\
\hline 111 & RCAT 0704 & $7.89 \pm 0.31$ & ABCDE \\
\hline 112 & RCAT 0705 & $7.41 \pm 0.31$ & ABCDEFGH \\
\hline 113 & RCAT 0706 & $8.21 \pm 0.31$ & A \\
\hline 114 & RCAT Wildcat & $6.17 \pm 0.31$ & BCDEFGH \\
\hline 115 & Richland & $7.56 \pm 0.31$ & ABCDEFG \\
\hline 116 & RIL 26 & $7.12 \pm 0.31$ & ABCDEFGH \\
\hline
\end{tabular}




\begin{tabular}{llll}
\hline 117 & RIL 28 & $6.81 \pm 0.31$ & ABCDEFGH \\
118 & RIL 3 & $6.97 \pm 0.31$ & ABCDEFGH \\
119 & RIL 4 & $7.35 \pm 0.31$ & ABCDEFGH \\
120 & RIL 47 & $7.17 \pm 0.31$ & ABCDEFGH \\
121 & RIL 5 & $6.75 \pm 0.31$ & ABCDEFGH \\
122 & RIL 67 & $7.23 \pm 0.31$ & ABCDEFGH \\
123 & RIL 89 & $6.84 \pm 0.31$ & ABCDEFGH \\
124 & RIL 90 & $6.42 \pm 0.31$ & ABCDEFGH \\
125 & RIL 93 & $6.45 \pm 0.31$ & ABCDEFGH \\
126 & S03-W4 & $6.60 \pm 0.31$ & ABCDEFGH \\
127 & SeCan 13-26C-HO & $6.56 \pm 0.31$ & ABCDEFGH \\
128 & SeCan 13-41C & $6.99 \pm 0.31$ & ABCDEFGH \\
129 & SeCan 08-15C & $7.12 \pm 0.31$ & ABCDEFGH \\
130 & SeCan 08-24C & $5.74 \pm 0.31$ & FGH \\
131 & SeCan 13-02C & $6.77 \pm 0.31$ & ABCDEFGH \\
132 & SeCan 13-04C & $6.93 \pm 0.31$ & ABCDEFGH \\
133 & SeCan 13-15C & $7.81 \pm 0.31$ & ABC \\
134 & SeCan 13-28C-HO & $7.03 \pm 0.31$ & ABCDEFGH \\
135 & SeCan 13-35C & $7.32 \pm 0.31$ & ABCDEFGH \\
136 & SeCan 13-84C-SCN & $6.86 \pm 0.31$ & ABCDEFG \\
137 & Venus & $5.96 \pm 0.31$ & FGH \\
138 & Wayne & $7.44 \pm 0.31$ & ABCDEFG \\
139 & Williams82 & $7.67 \pm 0.31$ & ABCDEF \\
140 & Williams & $7.50 \pm 0.31$ & ABCDEF \\
\hline
\end{tabular}

${ }^{\mathrm{a}} \alpha=0.05$ for standard error.

${ }^{b}$ Mean followed by the same letter are not significantly different according to Tukey's multiple range test $(\alpha=0.05)$. 